\title{
Loading regulation prevents phloem failure during drought and widens the range of phloem and stomatal traits
}

\author{
Ryan Stanfield ${ }^{1}$ and Megan Bartlett ${ }^{1}$ \\ ${ }^{1}$ University of California Davis
}

June 14, 2021

\begin{abstract}
Plant carbon transport is controlled by a multitude of parameters both internal and external to the sugar transporting phloem tissue. Sucrose transporter kinetics, conduit hydraulic resistance, and xylem water stress are all hypothesized to impact the amount of carbon delivered to sink tissues. However, the most important traits determining carbon export under drought are not well understood, especially for species with active molecular regulation of sucrose transport. This in turn limits our ability to assess species' resistances to phloem dysfunction under drought. Here, we use an integrated xylem-phloem-stomatal model to calculate leaf water potential from soil dryness, which is then used to determine gas exchange and phloem pressure gradients. We quantitatively compare the impacts of phloem loading kinetics, including feedbacks between loading and phloem pressure, phloem conduit resistances, and stomatal responses to water stress, on the total carbon export to sinks during drought. Regulating sucrose transporter kinetics which downregulates loading at high phloem pressures prevented runaway viscosity in the phloem sap and was the most important determinant of export rates under drought. In contrast to previous models, we found this feedback mechanism decoupled stomatal traits from phloem export efficiency during drought and increased the operational range of phloem hydraulic resistances.
\end{abstract}

\section{Introduction}

The phloem tissue is the "enigmatic central banker" appropriating and transporting carbon from the photosynthesizing sources to the carbon-consuming sinks (Ryan and Asao 2014). For the plant to "cash-out" the carbon-rich phloem sap for growth, respiration, or storage, the phloem must maintain a pressure gradient from source to sink to drive bulk flow (Münch 1930, van Bel 2003). A wide range of xylem and stomatal traits have been linked to maintaining plant hydraulic function under water stress and adapting plants to dry environments (Bartlett et al. 2016, Meinzer et al. 2009). However, the traits that confer phloem drought tolerance by maintaining pressure gradients for carbon transport under water stress are not well understood, due to the technical difficulty of measuring phloem transport in vivo (Savage et al. 2016, Jensen et al. 2016). Therefore, modeling approaches have been critical to assess the impacts of phloem anatomical traits and the hydraulic status of the plant on phloem transport (e.g., Jensen et al. 2012, Thompson and Holbrook 2003a,b). Coupled phloem-xylem transport models suggest that phloem transport is highly vulnerable to drought stress (Daudet et al. 2002, Hölttä et al. 2006, 2009, Lacointe and Minchin 2008) and that conservative stomatal behavior may reduce these impacts (Huang et al. 2018). However, although many of these past coupled models make phloem loading concentration dependent, they ignore Michaelis-Menten formalism for protein assisted active loading of sugars into source tissue. This is surprising considering work that shows up to $42 \%$ of species surveyed utilize an active sugar loading mechanism that would require membrane bound proteins (Rennie and Turgeon 2009); this loading mechanism includes economically important crops such as celery, tobacco, spinach, tomato, cotton, sunflower, and grapevine (Davies et al. 1999, Muller et al. 2014, Rennie and Turgeon 2009). The molecular mechanisms regulating active transport could provide the phloem with an additional level of control over transport (eg., Xu et al. 2018, Xu et al. 2020, Bush 2020), and the 
alteration of this control has been hypothesized to be important for genetic engineering of crops to increase yield (Braun et al. 2014). However, the mechanistic hydraulic consequences for phloem transport under stress are largely unknown. Thus, we conducted the first study to our knowledge evaluating the impacts of these regulatory mechanisms, and the interactive effects of transporter kinetics, phloem anatomy, and stomatal behavior on sugar translocation and export under drought.

In species with active phloem loading, the phloem conduit plasma membranes exhibit molecular regulatory mechanisms that change the capacity to load sugars for transport. In these species, membrane transporter proteins lining the phloem conduit membranes (sieve tubes) load sugars from the surrounding extracellular space (apoplasm) in leaf tissue (Rennie and Turgeon 2009). This decouples loading rates from the concentration gradient between the mesophyll and phloem (Lalonde et al. 2004, De Schepper et al. 2013, Milne et al. 2018). In contrast, passive loading requires there to be a favorable osmotic and pressure gradient between sugar producing mesophyll and sieve tube cells for phloem loading to occur (Rockwell et al. 2018, Schulz 2015). Active loading, meanwhile, does not depend on this gradient and instead relies on the enzyme kinetics of sucrose loading proteins such as SUCs or SUTs (Lalonde et al. 2004); the rate of loading is highly dependent on the loaders maximum loading rate or affinity for sucrose ( $\max$ or $K m$ values in Michalis-Menten formalism). Phloem in the unloading zone can use a similar process to actively export sugars to the sink tissue (Hackel et al. 2006, Gould et al. 2013, Santi et al. 2013, Zhang et al. 2004, 2006) which is hypothesized to extend along the entire transport pathway (Thompson 2006). This is evidenced by sucrose transporter localization in both passive (Payyavula et al. 2011) and active (Wiese et al. 2000) loaders throughout stem phloem. Drought, heat, and light intensity impact the transcript abundance and post-translational modification of sucrose transporters in phloem tissue (Durand et al. 2018, Medici et al. 2014, Xu et al. 2018, 2020). This may impact sucrose loading rates in phloem leading to downstream impacts on sugar export to sinks (Ainsworth and Bush 2011, Bush 2020). However, it remains unclear by what mechanism maximum loading and unloading rates across species and changes in sucrose transporter activity impacts the ability of phloem conduits to move carbon from source to sink, especially during drought.

Sucrose loading and unloading are critical to phloem drought responses. Drought stress impacts phloem transport by making it more difficult for water to enter the phloem. As water potential declines in the leaf xylem, the phloem must compensate by increasing sugar concentrations in the loading zone, to reduce osmotic potentials and attract water from the neighboring xylem (Konrad et al. 2019). This influx of water from the xylem generates the high turgor pressure in the loading zone that powers source-to-sink carbon transport. However, this presents a conundrum, since higher sucrose concentrations increase the viscosity of the phloem sap and, thus, the hydraulic resistance of the phloem (Sevanto 2014, 2018, Salmon et al. 2019). In well-watered conditions, sugar concentrations have been demonstrated to be optimal for efficient flow in many species (Jensen et al. 2013). However, under drought, the sugar concentrations needed to draw water from the xylem can increase viscosity to the point that the pressure gradient is unable to overcome phloem resistance, generating a positive feedback between loading and resistance that leads to transport failure (i.e., 'run-away viscosity') (Hölttä et al. 2009, Nikinmaa et al. 2013, Sevanto et al. 2014). The excessive pressure generated in the loading zone during this viscosity ramp up may also conceivably cause leakage of sucrose back out into the apoplasm, lowering overall transport efficiency, but this to our knowledge has yet to be tested. Reducing phloem turgor by experimentally imposing osmotic stress has been shown to increase loading rates (Smith and Milburn 1980), indicating that active-loading species can regulate loading rates in response to environmental conditions, sensed via the phloem water status. However, the impacts of phloem loading regulation to the 'run-away viscosity' problem in the context of drought is unknown.

Since a run-away viscosity event is due to excessive resistance occurring along the transport pathway, the structural resistance of the sieve tube may also impact this type of transport failure. However, a recent meta-analysis shows that the sieve tube anatomical resistance of a species bears little relation to where it is located across biomes (Liesche et al. 2017). This suggests that the availability of water to the plant shows little relation to its phloem anatomical properties. This is surprising as increased phloem structural resistance should make the plant more vulnerable to run-away viscosity, especially during drought. Structural aspects of the phloem that contribute to resistance may be in the form of its cell diameter and the porosity of their end 
walls (sieve plates) (e.g., Mullendore et al. 2010, Stanfield et al. 2019). In addition, the scaling of the conduits from source-sink may also play a role to minimize resistance and maintain adequate pressure gradients in both leaves and stems (Carvalho et al. 2017, Savage et al. 2017); this scaling increases in magnitude as pathway resistance per unit length lowers in taller trees to maintain flow at great heights (Clerx et al. 2020). Thus, although there is evidence to suggest resistance scales to maintain carbon transport within a plant, linking this parameter across species and environmental conditions (e.g., drought) does not seem clear.

Previous models suggest that plants close stomata under drought partly to mitigate impacts on phloem transport. More isohydric stomatal behavior (i.e., stomatal closure under less severe water stress) prevented xylem water potentials from declining to the point that passive loading was osmotically unfavorable (Huang et al. 2018). When loading rates were assumed to equal photosynthetic rates, more isohydric stomatal behavior prevented phloem concentrations from reaching thresholds for runaway viscosity (Nikinmaa et al. 2013). These findings have suggested that phloem transport strongly constrains gas exchange during drought. However, previous work has not addressed the potential for feedbacks between loading, plant water status, and architecture to prevent runaway viscosity and decouple stomatal behavior from phloem transport in active-loading species. Elucidating how stomatal behavior, phloem loading kinetics, and phloem structure interact to determine sucrose export to sinks under drought is crucial to identify the key traits conferring stress tolerance to carbon transport. These traits could then be applied to assess species' vulnerabilities to carbon starvation under the drier conditions expected under climate change or develop crop cultivars with more drought tolerant carbon transport systems.

Previous models have addressed how aspects of water deficit (Hölttä et al. 2006, 2009, Zhou et al. 2019), phloem architecture (Hölttä 2009, Jensen et al. 2012, Stanfield et al. 2019), loading and unloading kinetics (De Schepper and Steppe 2010, Hölttä et al. 2006, Goeschl and Han 2020), and stomatal behavior (Nikinmaa et al. 2013, Huang et al. 2018) impact phloem transport. However, they have not synthesized these components to quantify the relative importance of these variables to sucrose export under drought. The overall goal of this model is to determine how phloem anatomy, transporter kinetics and stomatal control traits influence sugar transport under a variety of plant water statuses. Specifically, this study addresses the questions: 1) what are the soil water potential thresholds that limit sugar export from the phloem in apoplasmic loading and unloading species? 2) how are these thresholds impacted by changes in phloem loading and unloading kinetics, phloem hydraulic resistance and sucrose leaking back out of the loading zone? and 3) how does stomatal behavior impact sugar export under water stress? We address these questions by integrating a stomatal-hydraulic model (modified from Bartlett et al. 2019) that calculates leaf water potentials and gas exchange rates from environmental and hydraulic trait inputs. We then combine this with a simple phloem transport model (similar to the axial transport model of DeSchepper and Steppe 2010) that calculates phloem pressure gradients and flow rates from leaf sucrose concentrations and water potentials, using the Michaelis-Menten enzyme formalism to represent active loading and unloading (Fig. 1).

\section{Materials and Methods}

\section{Model overview}

Conceptually, the model can be divided into three components: plant water status, gas exchange and phloem transport (Fig. 1). The plant water status component calculates the leaf mesophyll and xylem water potentials $\left(\Psi_{\mathrm{m}}\right.$ and $\left.\Psi_{\mathrm{x}}\right)$ from an input soil water potential $\left(\Psi_{\mathrm{s}}\right)$ and gas exchange and hydraulics. The gas exchange component calculates photosynthesis from the stomatal aperture, which is determined from the leaf water status $\left(\Psi_{\mathrm{m}}\right)$. The phloem transport component calculates a source - sink phloem concentration and pressure gradient generated from the Michaelis-Menten kinetics of loading/unloading sucrose and the water stress experienced by the phloem $\left(\Psi_{\mathrm{x} \text { or }} \Psi_{\mathrm{s}}\right)$. Here we assume the plant is an apoplasmic loader and unloader.

Plant water status and gas exchange

We separated the plant into two hydraulic elements, the mesophyll of a single leaf and the root-to-leaf xylem network, to capture the protective effect of vulnerability segmentation (Tyree and Ewers 1991). The leaf accounts for at least 30\% of whole-plant hydraulic resistance, with the mesophyll tissue accounting for 
about half of this resistance (Sack and Holbrook 2006, Scoffoni et al. 2011). This generates a strong water potential gradient across the mesophyll that buffers the xylem and phloem against water stress. We adapted the water balance equations from Sperry et al. (1998) to calculate the mesophyll and xylem water volume at each timestep:

$\frac{d W_{m}}{\mathrm{dt}}=\int_{\Psi_{m}}^{\Psi_{x}} K_{m} d \Psi-g_{s}$ VPD LAEqn 1a

$\frac{d W_{x}}{\mathrm{dt}}=K_{x}\left(\Psi_{s}-\Psi_{x}\right)-\int_{\Psi_{m}}^{\Psi_{x}} K_{m} d \Psi=0$ Eqn $1 \mathrm{~b}$

where $W$ is the water volume, $\Psi$ is the water potential, and $K$ is the hydraulic conductance of the mesophyll (subscript $m$ ) and xylem (subscript $x$ ). $V P D$ and $\Psi_{\mathrm{s}}$ are the environmental parameters, the vapor pressure deficit and soil water potential, respectively; $g_{s}$ is the stomatal conductance, and $L A$ is the area of a single leaf (see Table 1 for constant parameter values and Table 2 for the parameters varied across simulations). Here we assumed the water volume in the mesophyll changes over time, while the xylem is at steady-state (i.e., $\left.\frac{d W_{x}}{d t}=0\right)$.

The mesophyll water volume is converted to a relative water content by dividing by the maximum water volume $\left(\mathrm{RWC}_{m}=\frac{W_{m}}{V_{s a t, m}}\right)$, and then to a water potential through the pressure-volume relationships:

$\Psi_{m}=\{$

$\frac{\pi_{m}}{\mathrm{RWC}_{\mathrm{m}}}$

$$
\begin{array}{lc}
\frac{\pi_{0}\left(1-a_{f}\right)}{\mathrm{RWC}_{\mathrm{m}}-\mathrm{a}_{f}}-\pi_{o}-\varepsilon\left(1-\frac{1-a_{f}}{\mathrm{RWC}_{\mathrm{m}}-\mathrm{a}_{f}}\right) & \Psi_{m}>\pi_{\mathrm{tlp}} \\
\Psi_{m} \leq \pi_{\mathrm{tlp}}
\end{array} ; \text { Eqn } 2
$$

where $\pi_{o}, \pi_{\tau \lambda \pi}, a_{f}$, and $\epsilon$ are the leaf pressure-volume curve parameters of osmotic potential at full hydration turgor loss point, apoplasmic fraction, and cell wall modulus of elasticity, respectively (Bartlett et al. 2012). We considered the effects of mesophyll sugar content on water relations to be outside the scope of this study, and, thus, we assumed here that $\pi_{\mathrm{o}}$ was constant.

Water flow through the mesophyll was determined by integrating the mesophyll vulnerability curve:

$K_{m}=\frac{K_{\max , m}}{1+e^{-\alpha\left(\Psi_{m}-\Psi_{50, m}\right)}}$ Eqn 3

where $K_{\max , \mathrm{m}}$ is the maximum hydraulic conductance of the mesophyll, normalized by leaf area, $\alpha$ is a shape parameter, and $\Psi_{50, \mu}$ is the mesophyll water potential at which $50 \%$ of conductance is lost. To simplify these calculations, we used a sufficiently negative xylem $\Psi_{50}$ value $(-2 \mathrm{MPa})$ to assume $K_{\mathrm{x}}$ was constant and equal to the maximum xylem conductance $\left(K_{\max , \mathrm{x}}\right)$ over the range of xylem water potentials in these simulations.

We calculated $g$ s from the assumption that mesophyll water stress induces stomatal closure:

$g_{s}=\frac{g_{\max }}{\left.1+e^{-a g s\left(\Psi_{m}-g_{s} \Psi\right.} \Psi_{0}\right)}$ Eqn 4

where $g_{\max }$ is the maximum stomatal conductance, ags is the shape parameter for this relationship, and $g$ s $\Psi_{50}$ is the mesophyll water potential inducing $50 \%$ stomatal closure. Photosynthesis $(A$ net $)$ was then calculated fromg $\mathrm{s}$ based upon an extrapolation of the original Farquhar equations (Farquhar et al. 1980). We assumed that light was constant and non-limiting for photosynthesis over these simulations.

At the beginning of each timestep, $\Psi_{m}$ was calculated from the change in mesophyll volume over the previous timestep (Eqns 1a, 2). Mesophyll water flow was then calculated by integrating the mesophyll vulnerability curve over water potential, bounded by the new $\Psi_{m}$ and the $\Psi_{x}$ from the previous timestep (Eqns 1, 3). Stomatal conductance $\left(g_{s}\right)$ was then calculated from the new $\Psi_{m}$ (Eqn 4 ), and $\Psi_{x}$ was updated from the new mesophyll water flow

$\Psi_{x, t}=\Psi_{s}-\frac{\int_{\Psi_{m, t}}^{\Psi x, t-1} K_{m, t} d \Psi}{K_{\max , x}}$ Eqn 5 where $t$ indicates the current timestep and used to determine the new xylem flow $\left(K_{\max , x}\left(\Psi_{s}-\Psi_{x}\right)\right)($ Eqn $1 \mathrm{~b})$. The new mesophyll flow and $\mathrm{g}_{\mathrm{s}}$ values were then supplied to Eqn 1a to update the mesophyll volume for the next timestep. We ran the model at a 1 s timestep over $12 \mathrm{hr}$ simulations to achieve steady-state solutions, which were reported as the model results. 


\section{Phloem Transport}

The mass of sucrose in the mesophyll $\left(S_{m}\right)$ was increased by photosynthesis and reduced by loading into the phloem companion cells via sucrose transporters:

$\frac{\mathrm{dS}_{m}}{\mathrm{dt}}=A_{\text {net }} L A-L_{\text {sucL }}$ LAEqn 6

where $L_{\text {sucL }}$ is the loading rate per unit leaf area. To simplify the model, we assumed all the sugar produced by photosynthesis is exported into the apoplasmic space surrounding the sieve element/companion cell complexes of the loading zone, and thus available for phloem loading. For loading (subscript $i=L$ ) or unloading (subscript $i=U$ ), $L$ suc,i was calculated from the Michalis-Menten formalism for enzyme kinetics:

$L_{s u c, i}=V_{\max , i} \frac{C}{M_{S}+C}$ Eqn $7 \mathrm{a}$

$C_{m}=\frac{S_{m}}{W_{m}}$ Eqn $7 \mathrm{~b}$

where $V_{\max , i}$ is the maximum loading or unloading rate of the sucrose transporters, normalized by leaf area, and $M_{S}$ is a shape parameter capturing transporter affinity for sucrose. $C$ is either $C_{m}$, the sucrose concentration in the mesophyll outside the loading zone, or $C_{p U}$, the sucrose concentration in the unloading phloem zone. $W_{\mathrm{m}}$ is the mesophyll water volume (Eqn 1a). We assumed the transport phloem is impermeable, and water and sucrose are only exchanged in the loading and unloading zones.

Loading increases the mass of sucrose in the phloem loading zone $\left(S_{p, L}\right)$, which is transported to the unloading zone or leaked back into the mesophyll through diffusion

$\frac{\mathrm{dS}_{p, L}}{\mathrm{dt}}=L_{\mathrm{SUCL}} L A-E_{s}-S_{l} \operatorname{Eqn} 8 \backslash n$ where $E_{s}$ is the mass flow rate of sucrose transport $\left(\mathrm{g} \mathrm{s}^{-1}\right)$ and $\mathrm{S}_{l}$ is the mass flow rate of leakage. $E_{s}$ is calculated from the volumetric flow rate of the phloem sap $\left(F_{p} ; \mathrm{m}^{3} \mathrm{~s}^{-1}\right)$ and sucrose concentration in the loading zone $\left(C_{p, L} ; \mathrm{mol} \mathrm{m}^{-3}\right)$ :

$E_{s}=F_{\mathrm{p}} C_{p, L} \mathrm{~mm}$ Eqn $9 \mathrm{a}$

$C_{p, L}=\frac{S_{p, L}}{W_{p}}$ Eqn $9 \mathrm{~b}$

where $m m$ is the molar mass of sucrose and $W_{p}$ is the maximum water volume in the loading zone. Thompson and Holbrook (2003a) found that accounting for changes in phloem volume did not substantially impact the flux of sucrose through the transport pipeline. Thus, we made the simplifying assumption that $W_{p}$ was constant at the maximum phloem cell volume, so that $C_{p L}$ only varied with the mass of sucrose. We calculated $W_{p}$ from the mean sieve element area, measured for a Populus tremula $x$ alba leaf (Carvalho et al. 2017), and the total vein length in a grapevine leaf, as a representative apoplasmic loader (Pagano et al. 2016), assuming all leaf phloem is included in the loading zone. We calculated leakage as:

$S_{l}=L_{\text {leak }} L A\left(C_{p, L}-C_{m}\right)$ Eqn 10

where $L_{\text {leak }}$ is the membrane permeability of the loading zone to sucrose diffusion $\left(\mathrm{m} \mathrm{s}^{-1}\right)$, and the concentration gradient is the driving force for sucrose leakage.

The sucrose concentration determines the osmotic potential $\left(\pi_{i}\right)$ in the loading $(\mathrm{L})$ or unloading zone $(\mathrm{U})$

$\pi_{i}=-R c T C_{p, i}$ Eqn 11

where $R c$ is the gas constant and $T$ is the temperature within the phloem loading area. Following Thompson and Holbrook (2003b), we made the simplifying assumption that the water potential of the phloem loading zone equilibrates with the xylem water potential $\left(\Psi_{\mathrm{x}}\right)$ when the phloem is at steady state. Further, we estimate that the anatomical dimensions, osmotic strength, and enhanced permeability due to aquaporins (Muries et al. 2013) of our loading zone has an RF value $>>1$ (see Thompson and Holbrook 2003b, Eqn 22 ), which equates to phloem in water potential equilibrium with the xylem. The turgor pressure in the loading or unloading zone $\left(P_{i}\right)$ was then determined from the water and osmotic potentials:

$P_{i}=\Psi_{x}-\pi_{i}$ Eqn 12 
noting that for determining the phloem pressure in the unloading zone, $\Psi_{s}$ is used. The volumetric phloem flow rate $\mathrm{F}_{\mathrm{p}}\left(\mathrm{m}^{3} \mathrm{~s}^{-1}\right)$ was calculated from the pressure difference between the loading $\left(\mathrm{P}_{\mathrm{L}}\right)$ and unloading $\left(\mathrm{P}_{\mathrm{U}}\right)$ zones and the hydraulic resistance of the phloem $(R$ conduit $)$

$F_{p}=\frac{P_{L}-P_{U}}{R_{\text {conduit }}}$ Eqn 13

which increased with the phloem sucrose concentration due to viscosity ( $v$ ) effects (see Appendix A), and integrated into a resistance formula:

$R_{\text {conduit }}=R p * v$ Eqn 14

where $R p$ is the resistance coefficient of the phloem conduit (see Table 2).

The velocity of sap flow $\left(V_{s}\right)$ was calculated by normalizing volumetric flow by conduit area

$V_{s}=\frac{\mathrm{Fp}}{\pi r^{2}}$ Eqn 15

where $r$ is the radius of the conduit.

The same processes then take place when the sucrose reaches the unloading zone, where unloading is determined from:

$\frac{\mathrm{dS}_{U}}{\mathrm{dt}}=E_{s}-L_{\mathrm{SUCU}} L A E q n 16$

We made the simplifying assumptions that the source and sink area $(L A)$ and the phloem volume in the loading and unloading zones $\left(W_{\mathrm{p}}\right)$ are equal.

Finally, we quantified sugar export $\left(S_{\text {tot }}\right)$ as the cumulative mass of sucrose unloaded over the simulation, as

$S_{\mathrm{tot}}=L A \int_{0}^{T} L_{\mathrm{SUCU}}(t) \mathrm{dtEqn} 17$

Model parameterizations to test hypotheses

We tested our hypotheses for the impacts of phloem hydraulic resistance and membrane transporter kinetics on phloem transport under water stress by varying the soil water potential $\left(\Psi_{\mathrm{s}}\right)$, phloem resistance to pure water $\left(R_{\mathrm{p}}\right)$, maximum loading and unloading rates $\left(V_{\max L}\right.$ and $\left.V_{\max U}\right)$, membrane permeability to sucrose leakage $\left(L_{\text {leak }}\right)$, and relationship between $V_{\max L}$ and the loading zone turgor across simulations (see Table 2 for parameter values). First, we selected $5 R_{\mathrm{p}}$ values that generated phloem pressures $\left(P_{\mathrm{L}}\right)$ from across the observed range (i.e., $0.6-2.4 \mathrm{MPa}$ ) (Turgeon 2010) for well-watered conditions (here, $\Psi_{\mathrm{s}}=0 \mathrm{MPa}$ ). Second, we varied $V_{\operatorname{maxL}}$ in simulations where unloading did not limit phloem transport (i.e., all sucrose that reached the unloading zone was exported in the same timestep; $V_{\max U}>>V_{\max L}$ ), and simulations where unloading was limiting (i.e., sucrose can build up over time in the unloading zone; $V_{\max U}[?] V_{\max L}$ ). Phloem pressure in the unloading zone was $0 \mathrm{MPa}$ in the "unloading unlimited" and $>>0 \mathrm{MPa}$ in the "unloading limited" simulations. Third, we tested $L_{\text {leak }}$ values measured for carrot callus tissue as an approximation for sucrose leakage out of loading specific phloem (Edelman and Schoolar 1971). Fourth, we imposed turgor limitations on loading by setting $V_{\max L}=0$ when $P_{\mathrm{L}}=2.4 \mathrm{MPa}$, which emerged as a consistent threshold for runaway viscosity (see Results). For all these simulations, we characterized responses to water stress by varying $\Psi_{\mathrm{s}}$ from -0.001 to $-1 \mathrm{MPa}$ at $0.1 \mathrm{MPa}$ intervals. We compared phloem pressure $\left(P_{\mathrm{L}}\right.$ and $\left.P_{\mathrm{U}}\right)$, velocity $\left(V_{s}\right)$, viscosity $(v)$, and total sucrose export $\left(S_{\text {tot }}\right)$ across these simulations.

To address the impacts of stomatal behavior on phloem transport, we varied the maximum stomatal conductance $(g \max )$ and mesophyll water potential threshold for $50 \%$ stomatal closure $\left(g_{\mathrm{s}} \Psi_{50}\right)$ values. During these simulations, we varied the range of phloem resistance coefficients, and loading rates (see Table 2) to determine the interactions between adjusting these parameters.

Meta-analysis on phloem resistance and leaf water potential

Finally, we performed a meta-analysis to address if total phloem resistance values correlated with plant water status and hydraulic traits. We extracted phloem resistance values from the dataset compiled by 
Liesche et al. (2017). For 22 woody angiosperm and gymnosperm species, we paired these data with the minimum mid-day leaf water potentials $\left(\Psi_{\min }\right)$ and stem water potential thresholds for $50 \%$ declines in hydraulic conductance (stem $\Psi 50$ ) compiled by Choat et al. (2012) and Bartlett et al. (2016). The stem $\Psi 50$ is a measure of xylem resilience to embolism (Tyree and Ewers 1991), with lower stem $\Psi 50$ values supporting higher conductivity (ie, water supply) under drought. Thus, we predicted that this metric would correlate with phloem structural architecture as lower stem P50 should allow phloem architecture to support higher resistances as water is less limiting in these species. Since the data were not normal for phloem resistance, we used the spearman rank method to compute our test statistics. First, we tested the correlation between leaf $\Psi_{\min }$ and phloem structural resistance to determine if phloem anatomy scales with the water stress of the plant. Next, we used a partial linear correlation to test if phloem resistance varies with stem $\Psi 50$ while holding $\Psi_{\min }$ constant. Statistical analysis was performed in R studio Version 1.2.5033 using the package ppcor.

\section{Results}

Phloem sap transport varies while sucrose export remains largely consistent under drought

Sugar export was constant for simulations with soil water potentials above the thresholds for runaway viscosity, and negligible for simulations below these thresholds (Fig. 2A). These thresholds depended strongly on the phloem hydraulic resistance, with the most resistant phloem ceasing to export sugar at the least negative water potentials (R4 and R5, Table 2).

Above these thresholds, sucrose export from the phloem was not impacted by soil water potential or phloem hydraulic resistance (Fig. 2A, R1 - R3). Over the course of these simulations, the sucrose concentration and turgor in the loading zone increased until phloem transport reached a steady-state equilibrium, where the mass of sucrose imported into the phloem equals the exported amount if $\mathrm{V}_{\operatorname{maxU}}>>\mathrm{V}_{\operatorname{maxL}}$ (i.e., unloading is not constrained). Because loading rates are independent of water stress in apoplasmic-loading species, all simulations converged on the same equilibrium import and export rates, unless the model was unable to reach steady-state conditions. Simulations that reached steady state showed steadily increasing viscosity with declining soil water potentials (Fig. 2B). This caused a drop in phloem velocity by $\sim 57 \%$ between the wettest and driest conditions for moderately resistant phloem (R3) (Fig. 2C), due to changes in the phloem resistance and source to sink pressure gradient. For the least resistant phloem (R1, circles; Fig. 2D), phloem pressure decreased with soil water potential, because the xylem water potential was decreasing at a greater rate than phloem osmotic potential (Fig. S1, green line). Pressures at the unloading area (base pressures) remained close to zero (all sugar was unloaded), signaling that unloading was not a limitation in these models. Increasing phloem resistance to moderate values (R2 - R3) increased the pressure required to overcome resistance to transport, producing higher phloem pressures overall and driving the trend of increasing pressures at lower soil water potentials.

The most resistant phloem (R4 and R5) was unable to achieve steady-state transport, which limited sucrose export at soil water potentials below -0.7 and $-0.2 \mathrm{MPa}$, respectively. As $\Psi_{\mathrm{s}}$ became more negative, the concentration in the loading zone and, thus, the phloem viscosity and hydraulic resistance increased exponentially (Fig. 2B, asterisks). Overcoming greater resistance requires a higher loading zone turgor, which further increases the phloem concentration and, thus, the viscosity and hydraulic resistance. This can create a positive feedback loop where no loading zone concentration is able to overcome the resultant hydraulic resistance to transport sucrose to the unloading zone; as viscous resistance increases, so too does turgor pressure. In other words, declines in sucrose osmotic potentials outpaced declines in xylem water potential and caused phloem turgor to increase with water stress (Fig. S1, pink line). The most resistant phloem experienced this runaway viscosity effect even at relatively mildly negative soil water potentials (R4 and R5, Fig. 2B). Below these water potentials, sucrose import outpaced export and phloem viscosity, resistance, and turgor built until transport stopped entirely and the simulation was unable to return numerical results (indicated by asterisks in Figs. $2 \& 3$ ). Notably, the phloem transport variables always increased to intractable values immediately after reaching a loading zone pressure of $2.4 \mathrm{MPa}$ (Fig. 2D). In these scenarios, sugar export from the phloem only proceeded for a small fraction of the 12-hour simulation. In sum, despite 
phloem failure in the most resistant scenarios, sucrose export remained constant across a wide range of soil water potentials (i.e., 0 to $-1 \mathrm{MPa}$ ) for moderate resistances.

Increasing the loading rate $\left(\mathrm{V}_{\operatorname{maxL}}\right)$ by $40 \%$ increased the amount of sucrose exported by up to $40 \%$ in wet soil conditions when unloading was unlimited (i.e., all sugars reaching the unloading zone are immediately exported) (Fig. 3A). These scenarios appeared to show a trade-off in which higher transport rates are favored in wetter conditions, but in drier conditions, a lower rate is optimal to prevent runaway viscosity. Increasing the maximum loading rate increased the concentration and pressure to the $2.4 \mathrm{MPa}$ threshold (Fig. S2, asterisks) for runaway viscosity and no steady state solutions were found under water-stressed conditions.

Faster loading produced runaway viscosity more easily in the scenarios where unloading was limited, with only the two lowest loading rates producing steady state solutions across a wide range of soil water potentials (Fig. 3B, black and gold lines). However, as $\mathrm{V}_{\operatorname{maxU}}$ approaches $\mathrm{V}_{\operatorname{maxL}}$ phloem export begins to lag what was being received in the loading area; we call this phenomenon an unloading limited scenario. In our unloading limited simulations, we set $\mathrm{V}_{\operatorname{maxU}}$ only $1 \%$ higher than $\mathrm{V}_{\operatorname{maxL}}$. Limiting unloading exacerbated runaway viscosity and reduced sucrose export for simulations with faster loading at even less negative soil water potentials (Fig. 3B).

Turgor regulation expands the operational range of phloem export under water stress

Halting sucrose loading at a turgor pressure of 2.4 MPa reduced the sensitivity of phloem transport to water stress and allowed sucrose transport to be maintained over a wider range of soil water potentials (Fig. 4). We selected 2.4 MPa as the loading threshold, since the model did not return steady state solutions at higher pressures (Fig. S2, asterisks). When the phloem was able to stop loading at this threshold, increasing the loading rate allowed sucrose export to be increased by at least $4 \%$ and up to $40 \%$ across all water potentials (Fig. 4A, red squares). Turgor regulation also eliminated the effects of the unloading limitation (Fig. 4B), with both unloading scenarios showing the same relationships between $\mathrm{V}_{\operatorname{maxL}}$ and sucrose export. Thus, a turgor-sensing loading mechanism (Fig. 4) allowed the phloem to operate effectively over a wider range of soil water potentials.

This feedback mechanism also allowed for a wider range of phloem resistance values. Under turgor pressure regulated loading, and at the highest $\mathrm{V}_{\text {maxL }}$, we varied conduit resistance from $25 \%-145 \%$ (R1 to R5; Fig. 5 ). The lowest resistance conduit maintained the highest sucrose unloaded across the entire range of soil water potentials (Fig. 5, circles). As the resistance of the conduit increased, the total amount of sucrose exported declined. At the maximum resistance (Fig. 5, inverse triangles), sucrose export was only $51 \%$ of the lowest resistance simulation, when run at the lowest soil water potential $\left(\Psi_{\mathrm{s}}=-1 \mathrm{MPa}\right)$. Despite this reduction, the highest resistance phloem pathway was still able to export sugar while under turgor loading regulation (Fig. 5), while it would export none without this regulation (Fig. 2).

\section{Evaluating the impact of stomatal control over sucrose export}

Increasing stomatal conductance under water stress reduced sucrose export in some scenarios, but the impacts of the phloem loading kinetics and hydraulic resistance were considerably stronger (Fig. 6). First, we compared the effects of $g_{\max }$ and $g_{s} \Psi_{50}$ on sugar export at the most extreme soil water potentials (i.e., -1 and -0.001 MPa) for different phloem hydraulic resistances (R1 \& R4). A more negative gs $\Psi_{50}$ (Fig. 6A) and higher $\mathrm{g}_{\max }$ (Fig. 6B) reduced sucrose export under water stress for the most resistant phloem (R4, diamonds). These stomatal traits are consistent with anisohydric plants, which keep stomata open despite drought conditions. However, the stomatal traits had no impact on export for less resistant phloem (R1, circles).

Overall, while increasing sucrose loading rate increased export by up to $\sim 40 \%$, changing stomatal behavior changed export by at most $\sim 6 \%$. However, the higher loading rate made the stomatal effects more important - i.e., export starts to decline with 'riskier' stomatal behavior. In addition, under well-watered conditions, neither phloem resistance nor stomatal behavior strongly affected sucrose export (Fig. 6C, D). Instead, increasing the loading rate had the greatest impact on export, and plants only suffered reduced export with 
high phloem pathway resistances (red diamonds) while experiencing drought (Fig. 6 A, B).

Assessing the impact of phloem leakiness on phloem transport

Some sucrose may be leaked back out of the phloem membrane by diffusion, and we sought to determine whether this leakage is consequential for export efficiency. At modest soil water deficits (-0.5 MPa), the medium resistance scenario increased sucrose leakage by $80 \%$ compared to the lowest resistance (i.e., R1 vs. R3) (Fig. 7). However, this loss was negligible, as $\sim 10$ billion grams of sucrose would be exported before $\sim 1 \mathrm{~g}$ leaked out of the loading phloem. Thus, the tendency of sucrose to leak out of the loading area by diffusion was determined to be of minimal consequence.

Meta-analysis of phloem architecture and plant hydraulic traits

We conducted a meta-analysis to evaluate relationships between phloem and hydraulic (xylem) architecture and the maximum water stress species typically experience in natural conditions. First, phloem resistance, calculated from sieve element anatomy, was not significantly correlated with maximum water stress, defined from the seasonal minimum mid-day leaf water potential $\left(\Psi_{\mathrm{MD}}\right)\left(\mathrm{r}_{\mathrm{s}}=-0.241, \mathrm{~N}=20, \mathrm{p}\right.$ [?] 0.05). Further, phloem resistance was not significantly correlated with xylem embolism resistance (stem $\Psi_{50}$ ) when holding $\Psi_{\mathrm{MD}}$ constant, to account for the independent effects of environmental water stress on both variables $\left(\mathrm{r}_{\mathrm{s}}=\right.$ $-0.492, \mathrm{~N}=20$, p [?] 0.05).

\section{Discussion}

Regulation of transporter kinetics were the main driver of maintaining sugar export in a variety of conditions, followed by changes in phloem pathway resistance, and finally changes in leaf stomatal traits. This importantly signals that stomatal control is decoupled from phloem transport in an apoplasmic loader that regulates its turgor.

\section{Sucrose export is maintained under drought when loading is stopped at high phloem pressures}

Our model showed that setting a turgor threshold for loading prevented the buildup of sugars that causes runaway viscosity, reducing the impacts of water stress on sugar transport for highly resistant phloem. Turgor-regulated loading also allowed plants to benefit from faster loading in well-watered conditions without a trade-off on transport during drought. Consistent with these findings, previous work has shown that sucrose loading and unloading rates are sensitive to phloem turgor. Exposing the phloem to membrane-impermeable sugars (i.e., sorbitol or mannitol) reduces the apoplasmic water potential outside the phloem and draws water from the phloem, lowering phloem turgor (Smith and Milburn 1980). These treatments upregulated sucrose loading in leaf discs from castor bean and unloading in seed coats for beans and root discs of beets (Smith and Milburn 1980, Patrick 1994, Bell and Leigh 1996).

Several mechanisms could allow for turgor-regulated transport by altering the abundance of sucrose transporters in the sieve tube plasma membranes. First, changes in phloem turgor could trigger a hormonal signaling cascade that alters transporter expression or post-translational modification (Patrick et al. 2001). Water stress impacts the transcript abundance of phloem loading sucrose transporters (Xu et al. 2018). Sucrose transporter activity is also highly dependent on post-translational modification. Sucrose loading proteins degrade from the plasma membrane in as little as four hours (Liesche et al. 2011) and loading activity can be altered by external conditions. For instance, ubiquitination of these proteins increases their degradation rate, while phosphorylation increases their affinity for sucrose in plants exposed to differing light (direction species dependent) (Xu et al. 2020). Second, the same mechanisms could regulate the proton motive force for sucrose transport (Patrick et al. 2001). In pea leaves, mannitol treatments reduced phloem pressure and the $\mathrm{pH}$ in the adjacent xylem, while increasing phloem sucrose uptake (Estruch 1989). This suggests that a lower turgor led the phloem to upregulate proton transporter activity to increase the proton motive force for sucrose loading. Finally, turgor could have direct biophysical impacts on loading, as increasing cell turgor compresses the plasma membrane, which could constrain the permeability of membrane-bound sucrose or proton transporters (Coster et al. 1977). We found that a phloem turgor sensing mechanism would 
be essential for plants to maintain sugar transport in drought conditions, especially when their pathway resistance makes them more vulnerable to drought-induced failure. Thus, it will be critical for future studies to investigate the environmental catalysts behind the molecular regulation of sucrose transporters, and the consequences for phloem transport efficiency.

Recent modeling work also supports an important role for turgor-dependent membrane transport kinetics in phloem drought responses (Goeschel and Han 2020). This model assumes that the phloem downregulates unloading under water stress to prevent turgor from becoming negative in the unloading zone (Goeschel and Han 2020). However, this assumption was necessary for their simulations to capture observed responses of phloem concentration and velocity to water stress, which our model showed without turgor-dependent kinetics (Fig. 2). Without unloading regulation, the Goeschel model allows the unloading zone to reach negative turgor, so that a decline in plant water potential imposes the same decline in unloading zone turgor. This results in a maintenance of the source-to-sink pressure gradient and, thus, phloem concentration and velocity. Conversely, their equation to limit unloading maintained positive turgor at the unloading zone, causing the pressure gradient and consequently concentration and velocity to change with plant water potential. This change in velocity during drought is consistent with recent empirical measurements (Hesse et al. 2019, Dannoura et al. 2019). By contrast, our model prevents unloading zone turgor from falling below $0 \mathrm{MPa}$, since negative cellular turgor has never been recorded and has no clear biophysical meaning (Tyree 1976). If we remove this limitation, our results are similar to the simulations from Goeschel and Han (2020) without turgor-dependent unloading (data not shown). However, our model diverges from theirs by suggesting that turgor feedbacks on transport are important to prevent runaway viscosity under water stress, rather than a necessary condition to explain all phloem responses under normal conditions (Goeschel \& Han 2020).

Phloem resistance is an important parameter for phloem failure, not export efficiency

Apart from the regulation of sucrose transporter kinetics, the next most influential trait in regulating translocation during drought is phloem pathway resistance. Using our higher phloem resistance values (R4- R5), we found that phloem could not operate under moderate drought stress of soil $\Psi=-1 \mathrm{MPa}$ without regulation of membrane transporters. Based on these findings, we hypothesize that phloem resistance within each organ of the plant has a functional window, past which phloem failure occurs. However, our meta-analysis shows that drought exposure and phloem resistance are not correlated across a range of woody species. Thus, although phloem architecture may scale within the source to sink phloem pathway of an individual plant, there is no evidence to support that water stress is a strong selector for phloem architecture (as stated by Liesche et al. 2017).

Modeled phloem resistance could increase by 1 order of magnitude due to the occurrence of callose blockage at sieve plates in comparison to plates which are free of callose (Stanfield et al., 2019), or up to $20 \%$ due to p-protein agglomerations (Froelich et al. 2011). Insect attack (Hao et al. 2008) leads to callose blockages, and defoliation due to insects may reduce sieve tube diameters by up to $20 \%$ (Hillabrand et al. 2019) which would incur a large resistance to sap transport. The sieve tube has been hypothesized to compensate for these blockages by increasing its source-sink pressure differential (Knoblauch et al. 2014) or increasing phloem area and/or decreasing height by not growing as tall (Hölttä et al. 2006, 2009). Trees which cannot lower height instead increase phloem conducting area to lower resistance (Clerx et al. 2020) or change sieve plate allometry from source to sink (Savage et al. 2017). These structural remedies lower resistance and potentially alleviate the chances of phloem failure during drought as described in our model.

Previous models (including ours) largely assume that long distance pressure gradients drive Hagen-Poiseuille flow in the phloem, which may not be the case if sieve tubes are highly permeable to radial water flow (Sevanto 2014, Pfautsch et al. 2015). This distinction would change the mechanism for phloem failure under water stress, where phloem transport under extensive radial water exchange would fail from turgor loss and structural collapse in the sieve tubes instead of runaway viscosity (Sevanto 2014). In this scenario, a sieve tube with greater radial water exchange would exhibit greater water influx and faster sap flow under well-watered conditions, but greater water efflux and increased risk for turgor loss and cell collapse during drought. Sieve 
tubes are lined with aquaporins along the source-sink pathway (Stanfield et al. 2017), which is consistent with this hypothesis, especially if aquaporins are unable to use gating mechanisms (e.g., Tornroth-Horsefield et al. 2006) to rapidly prevent phloem water efflux under drought. However, molecular regulation is key to prevent drought-induced phloem failure from either mechanism. Future experiments will need to distinguish these hypotheses through assimilate tracing during drought, followed by anatomical studies to determine if phloem cell collapse occurred.

\section{Sucrose export is largely decoupled from stomatal behavior by molecular regulation of phloem loading}

In contrast to previous work (Huang et al. 2018), our model showed that making stomatal behavior more conservative (isohydric) to limit declines in xylem water potential had little impact on sucrose export under drought in simulations with active molecular regulation of loading. The only time that an impact was found under drought conditions was when simulating a high phloem resistance; in these scenarios, changing from an extremely anisohydric strategy (e.g., gs $\Psi 50=-2.2 \mathrm{MPa}$ ) to an extremely isohydric strategy (e.g., gs $\Psi 50$ $=-0.2 \mathrm{MPa}$ ) increased sucrose export by $\sim 6 \%$. However, this isohydric advantage was only possible through higher loading rates supported by pressure regulated sucrose transporters. If sucrose transporters could not be regulated in the phloem, then our model predicts stomata would have the impact of increasing the susceptibility to transport failure instead of adjusting the amount of sucrose exported. Huang et al. (2018) found that, for symplasmic loaders, maximizing the profit ratio between the sucrose exported by the phloem and produced by photosynthesis constrained gas exchange during drought. Isohydric simulations were more "cost effective" by closing the stomata to save water when the passively-loaded phloem was unable to generate the loading zone concentrations needed for export from the leaf. In simulations where loading was only proportional to carbon supply in the mesophyll, analogous to an apoplasmic loader, stomatal closure under drought was necessary to prevent runaway viscosity (Nikinmaa et al. 2013). Our findings demonstrate that downregulating sucrose loading is an effective alternative to stomatal closure, suggesting that phloem constraints on stomatal responses to drought could vary between symplasmic and apoplasmic loaders, or between apoplasmic loaders with different relationships between phloem pressure and transporter activity. Future work is needed to evaluate these hypotheses and the potential consequences for plant water and carbon fluxes under climate change.

\section{Conclusions}

Regulating phloem turgor via intermittent pausing of sucrose loading expanded the operational range of water potentials plants could experience and still maintain transport. This molecular regulation mechanism also largely decoupled phloem transport from stomatal behavior, except for extremely resistive phloem, by avoiding runaway viscosity and maintaining phloem function under drought. This mechanism also reduced the effects of a high phloem pathway resistance on transport, producing a large window of values with functionally identical sugar export rates. This finding leads us to hypothesize that ecosystem water stress has selected for resistance values within this window, to avoid excessive resistance and phloem failure. Future work will need to evaluate the runaway viscosity effect or turgor collapse hypotheses as the main driver of phloem failure and determine the degree of radial water permeability between the adjacent vascular tissues during drought.

\section{Acknowledgements}

RCS thanks the Rossi Postdoctoral and Katherine Esau Postdoctoral fellowships for funding.

\section{References}

Ainsworth, E. A., \& Bush, D. R. (2011). Carbohydrate export from the leaf: a highly regulated process and target to enhance photosynthesis and productivity. Plant physiology , 155 (1), 64-69.

Bartlett, M. K., Detto, M., \& Pacala, S. W. (2019). Predicting shifts in the functional composition of tropical forests under increased drought and CO 2 from trade-offs among plant hydraulic traits.Ecology letters , 22 (1), 67-77. 
Bartlett, M. K., Klein, T., Jansen, S., Choat, B., \& Sack, L. (2016). The correlations and sequence of plant stomatal, hydraulic, and wilting responses to drought. Proceedings of the National Academy of Sciences , 113 (46), 13098-13103.

Bartlett, M. K., Scoffoni, C., \& Sack, L. (2012). The determinants of leaf turgor loss point and prediction of drought tolerance of species and biomes: a global meta-analysis. Ecology letters ,15 (5), 393-405.

Bell, C. I., \& Leigh, R. A. (1996). Differential effects of turgor on sucrose and potassium transport at the tonoplast and plasma membrane of sugar beet storage root tissue. Plant, Cell E3 Environment ,19 (2), 191-200.

van Bel, A. J. (2003). The phloem, a miracle of ingenuity. Plant, Cell \& Environment, 26 (1), 125-149.

Borstlap, A. C., \& Schuurmans, J. A. M. J. (2004). Sucrose transport into plasma membrane vesicles from tobacco leaves by $\mathrm{H}+$ symport or counter exchange does not display a linear component. The Journal of membrane biology, 198 (1), 31-42.

Braun, D. M., Wang, L., \& Ruan, Y. L. (2014). Understanding and manipulating sucrose phloem loading, unloading, metabolism, and signalling to enhance crop yield and food security. Journal of Experimental Botany , 65 (7), 1713-1735.

Carvalho, M. R., Turgeon, R., Owens, T., \& Niklas, K. J. (2017). The scaling of the hydraulic architecture in poplar leaves. New Phytologist, 214 (1), 145-157.

Chen, C., Yuan, Y., Zhang, C., Li, H., Ma, F., \& Li, M. (2017). Sucrose phloem unloading follows an apoplastic pathway with high sucrose synthase in Actinidia fruit. Plant Science, 255, 40-50.

Clerx, L. E., Rockwell, F. E., Savage, J. A., \& Holbrook, N. M. (2020). Ontogenetic scaling of phloem sieve tube anatomy and hydraulic resistance with tree height in Quercus rubra. American Journal of Botany .

Choat, B., Jansen, S., Brodribb, T. J., Cochard, H., Delzon, S., Bhaskar, R., .. \& Zanne, A. E. (2012). Global convergence in the vulnerability of forests to drought. Nature , 491 (7426), 752-755.

Coster, H. G., Steudle, E., \& Zimmermann, U. (1977). Turgor pressure sensing in plant cell membranes. Plant Physiology, 58 (5), 636-643.

Dannoura, M., Epron, D., Desalme, D., Massonnet, C., Tsuji, S., Plain, C., .. \& Gérant, D. (2019). The impact of prolonged drought on phloem anatomy and phloem transport in young beech trees. Tree physiology , 39 (2), 201-210.

Daudet, F. A., Lacointe, A., Gaudillere, J. P., \& Cruiziat, P. (2002). Generalized Münch coupling between sugar and water fluxes for modelling carbon allocation as affected by water status. Journal of Theoretical Biology , 214 (3), 481-498.

Davies, C., Wolf, T., \& Robinson, S. P. (1999). Three putative sucrose transporters are differentially expressed in grapevine tissues.Plant Science , 147 (2), 93-100.

De Schepper, V., De Swaef, T., Bauweraerts, I., \& Steppe, K. (2013). Phloem transport: a review of mechanisms and controls. Journal of experimental botany , 64 (16), 4839-4850.

De Schepper, V., \& Steppe, K. (2010). Development and verification of a water and sugar transport model using measured stem diameter variations. Journal of experimental botany , 61 (8), 2083-2099.

Durand, M., Mainson, D., Porcheron, B., Maurousset, L., Lemoine, R., \& Pourtau, N. (2018). Carbon sourcesink relationship in Arabidopsis thaliana: the role of sucrose transporters. Planta ,247 (3), 587-611.

Estruch, J. J., Peretó, J. G., Vercher, Y., \& Beltrán, J. P. (1989). Sucrose loading in isolated veins of Pisum sativum: regulation by abscisic acid, gibberellic acid, and cell turgor. Plant Physiology , 91 (1), 259-265. 
Farquhar, G. D., von Caemmerer, S. V., \& Berry, J. A. (1980). A biochemical model of photosynthetic CO 2 assimilation in leaves of C 3 species. Planta , 149 (1), 78-90.

Froelich DR, Mullendore DL, Jensen KH, Ross-Elliott TJ, Anstead JA, Thompson GA, Pélissier HC, Knoblauch M. 2011. Phloem ultrastructure and pressure flow: sieve-element-occlusion-related agglomerations do not affect translocation. The Plant Cell23, 4428-4445.

Goeschl, J. D., \& Han, L. (2020). A Proposed Drought Response Equation Added to the Münch-Horwitz Theory of Phloem Transport. Frontiers in Plant Science, 11.

Gould, N., Morrison, D. R., Clearwater, M. J., Ong, S., Boldingh, H. L., \& Minchin, P. E. (2013). Elucidating the sugar import pathway into developing kiwifruit berries (Actinidia deliciosa). New Zealand Journal of Crop and Horticultural Science , 41 (4), 189-206.

Hackel, A., Schauer, N., Carrari, F., Fernie, A. R., Grimm, B., \& Kühn, C. (2006). Sucrose transporter LeSUT1 and LeSUT2 inhibition affects tomato fruit development in different ways. The Plant Journal, 45 (2), 180-192.

Hao, P., Liu, C., Wang, Y., Chen, R., Tang, M., Du, B., ... \& He, G. (2008). Herbivore-induced callose deposition on the sieve plates of rice: an important mechanism for host resistance. Plant physiology , 146 (4), 1810-1820.

Hesse, B. D., Goisser, M., Hartmann, H., \& Grams, T. E. (2019). Repeated summer drought delays sugar export from the leaf and impairs phloem transport in mature beech. Tree physiology , 39 (2), 192-200.

Hillabrand, R. M., Hacke, U. G., \& Lieffers, V. J. (2019). Defoliation constrains xylem and phloem functionality. Tree physiology ,39 (7), 1099-1108.

Hölttä, T., Mencuccini, M., \& Nikinmaa, E. (2009). Linking phloem function to structure: analysis with a coupled xylem-phloem transport model. Journal of theoretical biology , 259 (2), 325-337.

Hölttä, T., Vesala, T., Sevanto, S., Perämäki, M., \& Nikinmaa, E. (2006). Modeling xylem and phloem water flows in trees according to cohesion theory and Münch hypothesis. Trees , 20 (1), 67-78.

Huang, C. W., Domec, J. C., Palmroth, S., Pockman, W. T., Litvak, M. E., \& Katul, G. G. (2018). Transport in a coordinated soil-root-xylem-phloem leaf system. Advances in water resources ,119, 1-16.

Jensen, K. H., Mullendore, D. L., Holbrook, N. M., Bohr, T., Knoblauch, M., \& Bruus, H. (2012). Modeling the hydrodynamics of phloem sieve plates. Frontiers in plant science, 3, 151.

Jensen, K. H., Savage, J. A., \& Holbrook, N. M. (2013). Optimal concentration for sugar transport in plants. Journal of the Royal Society Interface , 10 (83), 20130055.

Jensen, K. H., Berg-Sørensen, K., Bruus, H., Holbrook, N. M., Liesche, J., Schulz, A., . . \& Bohr, T. (2016). Sap flow and sugar transport in plants. Reviews of modern physics , 88 (3), 035007.

Knoblauch, M., Froelich, D. R., Pickard, W. F., \& Peters, W. S. (2014). SEORious business: structural proteins in sieve tubes and their involvement in sieve element occlusion. Journal of experimental botany , 65 (7), 1879-1893.

Lacointe, A., \& Minchin, P. E. (2008). Modelling phloem and xylem transport within a complex architecture. Functional Plant Biology , 35 (10), 772-780.

Lalonde, S., Wipf, D., \& Frommer, W. B. (2004). Transport mechanisms for organic forms of carbon and nitrogen between source and sink.Annu. Rev. Plant Biol. , 55 , 341-372.

Liesche, J., Krügel, U., He, H., Chincinska, I., Hackel, A., \& Kühn, C. (2011). Sucrose transporter regulation at the transcriptional, post-transcriptional and post-translational level. Journal of plant physiology , 168 (12), 1426-1433. 
Liesche, J., Pace, M. R., Xu, Q., Li, Y., \& Chen, S. (2017). Height-related scaling of phloem anatomy and the evolution of sieve element end wall types in woody plants. New Phytologist ,214 (1), 245-256.

Medici, A., Laloi, M., \& Atanassova, R. (2014). Profiling of sugar transporter genes in grapevine coping with water deficit. FEBS letters , 588 (21), 3989-3997.

Milne, R. J., Grof, C. P., \& Patrick, J. W. (2018). Mechanisms of phloem unloading: shaped by cellular pathways, their conductances and sink function. Current opinion in plant biology , 43 , 8-15.

Meinzer, F. C., Johnson, D. M., Lachenbruch, B., McCulloh, K. A., \& Woodruff, D. R. (2009). Xylem hydraulic safety margins in woody plants: coordination of stomatal control of xylem tension with hydraulic capacitance. Functional Ecology, 23 (5), 922-930.

Mullendore, D. L., Windt, C. W., Van As, H., \& Knoblauch, M. (2010). Sieve tube geometry in relation to phloem flow. The Plant Cell ,22 (3), 579-593.

Munch, E. (1930). Stoffbewegungen in der Pflanze.

Muries, B., Carvajal, M., \& del Carmen Martinez-Ballesta, M. (2013). Response of three broccoli cultivars to salt stress, in relation to water status and expression of two leaf aquaporins. Planta ,237 (5), 1297-1310.

Nikinmaa, E., Holtta, T., Hari, P., Kolari, P., Makela, A., Sevanto, S., \& Vesala, T. (2013). Assimilate transport in phloem sets conditions for leaf gas exchange. Plant, Cell \& Environment, 36 (3), 655-669.

Patrick, J. W. (1994). Turgor-dependent unloading of assimilates from coats of developing legume seed. Assessment of the significance of the phenomenon in the whole plant. Physiologia Plantarum ,90 (4), 645654.

Payyavula, R. S., Tay, K. H., Tsai, C. J., \& Harding, S. A. (2011). The sucrose transporter family in Populus: the importance of a tonoplast PtaSUT4 to biomass and carbon partitioning. The Plant Journal ,65 (5), 757-770.

Pfautsch, S., Renard, J., Tjoelker, M. G., \& Salih, A. (2015). Phloem as capacitor: radial transfer of water into xylem of tree stems occurs via symplastic transport in ray parenchyma. Plant physiology ,167 (3), 963-971.

Rennie, E. A., \& Turgeon, R. (2009). A comprehensive picture of phloem loading strategies. Proceedings of the National Academy of Sciences , 106 (33), 14162-14167.

Rockwell, F. E., Gersony, J. T., \& Holbrook, N. M. (2018). Where does Munch flow begin? Sucrose transport in the pre-phloem path. Current opinion in plant biology , 43 , 101-107.

Ryan, M. G., \& Asao, S. (2014). Phloem transport in trees. Tree Physiology , 34 (1), 1-4.

Sack, L., \& Holbrook, N. M. (2006). Leaf hydraulics. Annu. Rev. Plant Biol. , 57, 361-381.

Salmon, Y., Dietrich, L., Sevanto, S., Holtta, T., Dannoura, M., \& Epron, D. (2019). Drought impacts on tree phloem: from cell-level responses to ecological significance. Tree physiology ,39 (2), 173-191.

Savage, J. A., Beecher, S. D., Clerx, L., Gersony, J. T., Knoblauch, J., Losada, J. M., .. \& Holbrook, N. M. (2017). Maintenance of carbohydrate transport in tall trees. Nature plants ,3 (12), 965-972.

Savage, J. A., Clearwater, M. J., Haines, D. F., Klein, T., Mencuccini, M., Sevanto, S., .. \& Zhang, C. (2016). Allocation, stress tolerance and carbon transport in plants: how does phloem physiology affect plant ecology?. Plant, Cell \& Environment, 39 (4), 709-725.

Sevanto, S. (2014). Phloem transport and drought. Journal of experimental botany , 65 (7), 1751-1759.

Sevanto, S. (2018). Drought impacts on phloem transport. Current opinion in plant biology , 43 , 76-81. 
Sevanto, S., Mcdowell, N. G., Dickman, L. T., Pangle, R., \& Pockman, W. T. (2014). How do trees die? A test of the hydraulic failure and carbon starvation hypotheses. Plant, cell \& environment, 37 (1), 153-161.

Scoffoni, C., Rawls, M., McKown, A., Cochard, H., \& Sack, L. (2011). Decline of leaf hydraulic conductance with dehydration: relationship to leaf size and venation architecture. Plant Physiology ,156 (2), 832-843.

Stanfield, R. C., Hacke, U. G., \& Laur, J. (2017). Are phloem sieve tubes leaky conduits supported by numerous aquaporins?. American Journal of Botany, 104 (5), 719-732.

Stanfield, R. C., Schulte, P. J., Randolph, K. E., \& Hacke, U. G. (2019). Computational models evaluating the impact of sieve plates and radial water exchange on phloem pressure gradients. Plant, cell $\& 3$ environment , 42 (2), 466-479.

Thompson, M. V., \& Holbrook, N. M. (2003a). Application of a single-solute non-steady-state phloem model to the study of long-distance assimilate transport. Journal of Theoretical Biology , 220 (4), 419-455.

Thompson, M. V., \& Holbrook, N. M. (2003b). Scaling phloem transport: water potential equilibrium and osmoregulatory flow. Plant, Cell \& Environment, 26 (9), 1561-1577.

Thompson, M. V. (2006). Phloem: the long and the short of it. Trends in plant science, 11 (1), 26-32.

Tornroth-Horsefield, S., Wang, Y., Hedfalk, K., Johanson, U., Karlsson, M., Tajkhorshid, E., .. \& \& Kjellbom, P. (2006). Structural mechanism of plant aquaporin gating. Nature , 439 (7077), 688-694.

Turgeon, R. (2010a). The puzzle of phloem pressure. Plant physiology , 154 (2), 578-581.

Tyree, M. T. (1976). Negative turgor pressure in plant cells: fact or fallacy?. Canadian Journal of Botany , 54 (23), 2738-2746.

Tyree, M. T., \& Ewers, F. W. (1991). The hydraulic architecture of trees and other woody plants. New Phytologist , 119 (3), 345-360.

Weise, A., Barker, L., Kuhn, C., Lalonde, S., Buschmann, H., Frommer, W. B., \& Ward, J. M. (2000). A new subfamily of sucrose transporters, SUT4, with low affinity/high capacity localized in enucleate sieve elements of plants. The Plant Cell , 12 (8), 1345-1355.

Xu, Q., Chen, S., Yunjuan, R., Chen, S., \& Liesche, J. (2018). Regulation of sucrose transporters and phloem loading in response to environmental cues. Plant Physiology , 176 (1), 930-945.

Xu, Q., Yin, S., Ma, Y., Song, M., Song, Y., Mu, S., . . \& Liesche, J. (2020). Carbon export from leaves is controlled via ubiquitination and phosphorylation of sucrose transporter SUC2. Proceedings of the National Academy of Sciences , 117 (11), 6223-6230.

Zhang, L. Y., Peng, Y. B., Pelleschi-Travier, S., Fan, Y., Lu, Y. F., Lu, Y. M., .. \& \& Zhang, D. P. (2004). Evidence for apoplasmic phloem unloading in developing apple fruit. Plant Physiology ,135 (1), 574-586.

Zhang, X. Y., Wang, X. L., Wang, X. F., Xia, G. H., Pan, Q. H., Fan, R. C., .. \& Z Zhang, D. P. (2006). A shift of phloem unloading from symplasmic to apoplasmic pathway is involved in developmental onset of ripening in grape berry. Plant physiology, 142 (1), 220-232.

Zhou, X. R., Schnepf, A., Vanderborght, J., Leitner, D., Lacointe, A., Vereecken, H., \& Lobet, G. (2020). CPlantBox, a whole-plant modelling framework for the simulation of water-and carbon-related processes.in silico Plants, 2 (1), diaa001.

Table 1. Description of mathematical symbols used in the model.

\begin{tabular}{llll}
\hline Symbol & Definition & Value & Source \\
\hline af & $\begin{array}{l}\text { Apoplastic fraction } \\
\text { inside the leaf }\end{array}$ & 0.3 &
\end{tabular}




\begin{tabular}{|c|c|c|c|}
\hline Symbol & Definition & Value & Source \\
\hline ags & $\begin{array}{l}\text { Shape parameter } \\
\text { relating gs } \Psi_{50} \& \Psi_{\mathrm{m}}\end{array}$ & 2.0 & \\
\hline$A_{\text {net }}$ & $\begin{array}{l}\text { Carbon assimilation } \\
\text { through photosynthesis }\end{array}$ & - & \\
\hline$c_{a}$ & $\begin{array}{l}\text { Atmospheric } \mathrm{CO}_{2} \\
\text { concentration }\end{array}$ & 400 Parts Per Million & \\
\hline$C_{m}$ & $\begin{array}{l}\text { Concentration of } \\
\text { sucrose in mesophyll }\end{array}$ & - & \\
\hline$C_{p L, U}$ & $\begin{array}{l}\text { Concentration of } \\
\text { sucrose in phloem } \\
\text { loading (L) or } \\
\text { unloading (U) area }\end{array}$ & - & \\
\hline$E_{s}$ & $\begin{array}{l}\text { Rate of sucrose leaving } \\
\text { phloem loading area }\end{array}$ & - & \\
\hline$f$ & $\begin{array}{l}\text { Water flow through } \\
\text { mesophyll }(\mathrm{m}) \text { or } \\
\text { xylem }(\mathrm{x})\end{array}$ & - & \\
\hline$F p$ & $\begin{array}{l}\text { Volumetric flow rate of } \\
\text { phloem }\end{array}$ & - & \\
\hline$g_{\max }$ & $\begin{array}{l}\text { Maximum stomatal } \\
\text { conductance }\end{array}$ & $\begin{array}{l}400 \mathrm{mmol} \mathrm{m}{ }^{-2} \mathrm{~s}^{-1} \\
\text { (default) }\end{array}$ & \\
\hline$g_{s}$ & Stomatal conductance & - & \\
\hline $\mathrm{gs}_{50}$ & $\begin{array}{l}\text { Water potential of } \\
\text { mesophyll at } 50 \% \\
\text { stomatal closure }\end{array}$ & $-1.5 \mathrm{MPa}$ (default) & \\
\hline$K m, x$ & $\begin{array}{l}\text { Hydraulic conductance } \\
\text { of mesophyll }(\mathrm{m}) \text { or } \\
\text { xylem }(\mathrm{x})\end{array}$ & - & \\
\hline$M_{R}$ & $\begin{array}{l}\text { Michaelis-Menten } \\
\text { constant for Rubisco } \\
\text { affinity }\end{array}$ & 300 Parts Per Million & \\
\hline$K_{\max }$ & $\begin{array}{l}\text { Maximum hydraulic } \\
\text { conductance of the leaf }\end{array}$ & $20 \mathrm{mmol} \mathrm{m}^{-2} \mathrm{~s}^{-1} \mathrm{MPa}^{-1}$ & \\
\hline$M_{S}$ & $\begin{array}{l}\text { The affinity of the } \\
\text { sucrose molecule to the } \\
\text { SUT protein }\end{array}$ & $3.3 \mathrm{mM}$ & \\
\hline Leak & $\begin{array}{l}\text { The permeability rate } \\
\text { of the sieve tube } \\
\text { membrane to sucrose } \\
\text { by diffusion }\end{array}$ & $7.3 \mathrm{e}^{-17} \mathrm{~m} / \mathrm{s}$ (Default) & $\begin{array}{l}\text { Edelman and Schoolar } \\
(1971)\end{array}$ \\
\hline$L A$ & Leaf Area & $47.4 \mathrm{~cm}^{2}$ & \\
\hline$L_{\text {sucL }, U}$ & $\begin{array}{l}\text { Loading rate of sucrose } \\
\text { per unit tissue area for } \\
\text { the loading }(\mathrm{L}) \text { or } \\
\text { unloading }(\mathrm{U}) \text { area }\end{array}$ & - & \\
\hline$m m$ & Molar mass of sucrose & $342.3 \mathrm{~g} \mathrm{~mol}^{-1}$ & \\
\hline$F_{p}$ & Phloem flow rate & - & \\
\hline$P_{L, U}$ & $\begin{array}{l}\text { Phloem pressure in } \\
\text { loading (L) or } \\
\text { unloading zone (U) }\end{array}$ & - & \\
\hline
\end{tabular}




\begin{tabular}{|c|c|c|c|}
\hline Symbol & Definition & Value & Source \\
\hline$r$ & Radius of phloem conduit & $1.8 \mathrm{e}^{-5} \mathrm{~m}$ & $\begin{array}{l}\text { Esau 1962; Liesche et al. } \\
2017\end{array}$ \\
\hline$R c$ & Gas constant & $8.3 \mathrm{~m}^{3} \mathrm{pa} \mathrm{K}^{-1} \mathrm{~mol}^{-1}$ & \\
\hline$R_{\text {conduit }}$ & $\begin{array}{l}\text { Resistance of the } \\
\text { phloem conduit }\end{array}$ & - & \\
\hline$R_{L}$ & Leaf respiration rate & $0.25 \mu \mathrm{mol} \mathrm{C} \mathrm{m} \mathrm{m}^{-2} \mathrm{~s}^{-1}$ & \\
\hline$R p$ & $\begin{array}{l}\text { Structural resistance } \\
\text { coefficient of the } \\
\text { phloem }\end{array}$ & See Table 2 & \\
\hline$R W C_{m}$ & $\begin{array}{l}\text { Relative water content } \\
\text { of the mesophyll }\end{array}$ & - & \\
\hline$S l$ & $\begin{array}{l}\text { Leakiness of sucrose in } \\
\text { the phloem conduit }\end{array}$ & - & \\
\hline$S_{m}$ & $\begin{array}{l}\text { Mass of sucrose in } \\
\text { apoplastic space }\end{array}$ & - & \\
\hline$S_{p, b}$ & $\begin{array}{l}\text { Mass of sucrose inside } \\
\text { loading phloem (p) or } \\
\text { unloading phloem (b) }\end{array}$ & - & \\
\hline$S f$ & $\begin{array}{l}\text { Mass fraction of } \\
\text { sucrose in phloem sap }\end{array}$ & - & \\
\hline $\mathrm{t}$ & Run time of model & $12 \mathrm{hrs}$ & \\
\hline$T$ & Temperature & $293 \mathrm{~K}$ & \\
\hline$v$ & $\begin{array}{l}\text { Viscosity of phloem } \\
\text { conduit sap }\end{array}$ & - & \\
\hline$V_{c \max }$ & $\begin{array}{l}\text { Maximum } \\
\text { carboxylation rate }\end{array}$ & $40 \mu \mathrm{mol} \mathrm{m}{ }^{-2} \mathrm{~s}^{-1}$ & \\
\hline$V_{\operatorname{maxL}}$ & $\begin{array}{l}\text { Maximum rate of } \\
\text { sucrose uptake (phloem } \\
\text { loading) }\end{array}$ & $\begin{array}{l}1.58 \mathrm{e}^{-7} \mathrm{~mol} \mathrm{~m}^{-2} \mathrm{~s}^{-1} \\
\text { (default) }\end{array}$ & $\begin{array}{l}\text { Borstlap and } \\
\text { Schuurmans (2004) }\end{array}$ \\
\hline$V_{\max U}$ & $\begin{array}{l}\text { Maximum rate of } \\
\text { sucrose export (phloem } \\
\text { unloading) }\end{array}$ & $\begin{array}{l}\mathrm{V}_{\operatorname{maxL}} * 3 \text { (no } \\
\text { unloading limitation) }\end{array}$ & \\
\hline$V P D$ & $\begin{array}{l}\text { Vapor Pressure Deficit } \\
\text { of leaf }\end{array}$ & $9.9 \mathrm{e}-3$ & \\
\hline$V_{s}$ & $\begin{array}{l}\text { Velocity of sap in } \\
\text { phloem conduit }\end{array}$ & - & \\
\hline$V_{\text {sat }}$ & $\begin{array}{l}\text { Saturated water } \\
\text { content of the leaf }\end{array}$ & $33.3 \mathrm{mmol}$ & \\
\hline$v w$ & $\begin{array}{l}\text { Viscosity of pure water } \\
\text { @ } 200 \mathrm{C}\end{array}$ & 1.0 $\mathrm{e}^{-9} \mathrm{MPa} \mathrm{s}$ & \\
\hline$W$ & $\begin{array}{l}\text { Water volume of the } \\
\text { mesophyll }(\mathrm{m}) \text {, xylem } \\
(\mathrm{x}) \text {, or leaf }(\mathrm{l})\end{array}$ & 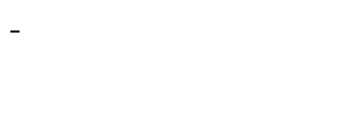 & \\
\hline$W_{p}$ & $\begin{array}{l}\text { Water volume inside } \\
\text { phloem }\end{array}$ & $3.57 \mathrm{e}^{-11} \mathrm{~m}^{3}$ & \\
\hline$\alpha$ & $\begin{array}{l}\text { Shape parameter for } \\
\text { determining mesophyll } \\
\text { conductance }\end{array}$ & 2 & \\
\hline$\Gamma$ & $\begin{array}{l}\text { Carbon Compensation } \\
\text { Point }\end{array}$ & 30 Parts Per Million & \\
\hline
\end{tabular}




\begin{tabular}{llll}
\hline Symbol & Definition & Value & Source \\
\hline$\epsilon$ & Modulus of elasticity & $15 \mathrm{MPa}$ & \\
& for mesophyll cell walls & \\
$\rho$ & Density of phloem sap & - \\
& Osmotic potential of & $-0.8 \mathrm{MPa}$ \\
& mesophyll at full & \\
& hydration & \\
& Osmotic potential of & - \\
& mesophyll & \\
$\pi_{\mu}$ & Osmotic potential of & - \\
& phloem @ loading (L) & \\
$\pi_{\Lambda, \Upsilon}$ & or unloading (U) zones & \\
& Turgor loss point & - \\
$\pi_{\tau \lambda \pi}$ & Mesophyll water & $-2.0 \mathrm{MPa}$ \\
$\Psi_{50, \mathrm{~m}}$ & potential at which 50\% & \\
& of the mesophyll & \\
& conductance is lost. & \\
$\Psi_{\mathrm{m}}$ & Water potential- & \\
$\Psi_{\mathrm{s}}$ & mesophyll & \\
$\Psi_{\mathrm{x}}$ & Water potential- soil & See Table 2 \\
& Water potential - & - \\
\hline
\end{tabular}

Table 2. Parameters which varied during the simulations.

\begin{tabular}{|c|c|c|}
\hline Symbol & Definition & Value \\
\hline Leak & $\begin{array}{l}\text { The permeability rate of the sieve } \\
\text { tube membrane to sucrose by } \\
\text { diffusion }\end{array}$ & $\begin{array}{l}4.6 \mathrm{e}^{-17} \mathrm{~m} / \mathrm{s} \text { (L1, carrot callose) } \\
2.92 \mathrm{e}^{-11} \text { (L2, chloroplast } \\
\text { membrane) }\end{array}$ \\
\hline$R p$ & $\begin{array}{l}\text { Structural resistance coefficient of } \\
\text { the phloem }\end{array}$ & $\begin{array}{l}1.58 \mathrm{e}^{20}(\mathrm{R} 1) 5.36 \mathrm{e}^{20}(\mathrm{R} 2) 6.30 \mathrm{e}^{20} \\
(\mathrm{R} 3) 7.24 \mathrm{e}^{20}(\mathrm{R} 4) 9.13 \mathrm{e}^{20}(\mathrm{R} 5)\end{array}$ \\
\hline$V_{\max L}$ & $\begin{array}{l}\text { Maximum rate of sucrose uptake } \\
\text { (phloem loading) }\end{array}$ & $\begin{array}{l}1.58 \mathrm{e}^{-7} \mathrm{~mol} \mathrm{~m}^{-2} \mathrm{~s}^{-1}(100 \%) 1.74 \mathrm{e}^{-7} \\
(110 \%) 1.90 \mathrm{e}^{-7}(120 \%) 2.06 \mathrm{e}^{-7} \\
(130 \%) 2.22 \mathrm{e}^{-7}(140 \%)\end{array}$ \\
\hline$V_{\max U}$ & $\begin{array}{l}\text { Maximum rate of sucrose export } \\
\text { (phloem unloading) }\end{array}$ & $\begin{array}{l}=\mathrm{V}_{\mathrm{MaxL}} * 3 \text { (no unloading } \\
\text { limitation) }=\mathrm{V}_{\operatorname{maxL}} * 1.01 \\
\text { (unloading only } 1 \% \text { higher than } \\
\text { loading) }\end{array}$ \\
\hline$\Psi_{\mathrm{s}}$ & Water potential of soil & $-0.001-(-) 1 \mathrm{MPa}$ \\
\hline$g_{\max }$ & $\begin{array}{l}\text { Maximum stomatal } \\
\text { conductance }\end{array}$ & $20-400 \mathrm{mmol} \mathrm{m}{ }^{-2} \mathrm{~s}^{-1}$ \\
\hline $\operatorname{gs} \Psi_{50}$ & $\begin{array}{l}\text { Water potential of mesophyll at } \\
50 \% \text { stomatal closure }\end{array}$ & $-0.2-(-) 2.2 \mathrm{MPa}$ \\
\hline
\end{tabular}

Figure Legends

Figure 1. Parameterization and conceptual schematic of the water and sugar transport model. The model inputs are shown in pink, while the outputs of the model are in red. The model first produces a xylem water potential based on the input soil water potential. This then generates a leaf mesophyll water potential that 
then determines a stomatal conductance. The conductance of stomata (large green ovals) is modulated by stomatal properties such as Gmax or Gs 450 , which then influences the amount of carbon that is assimilated through photosynthesis. The assimilated carbon then produces a sugar concentration in the mesophyll, which is then used for active phloem loading (symbolized by orange ovals). Phloem pressure in the loading zone was built by the osmotic potential overcoming the water potential of the xylem apoplast. Phloem outputs include sap velocity, viscosity, and pressure. Phloem characteristics which could be modified were structural resistance (Rphloem) or maximum sucrose import/export rate (Vmax load or Vmax unload). The ultimate result was the amount of sucrose that was exported into sink tissue.

Figure 2. Phloem output parameters modeled over varying soil water potentials and phloem resistance coefficients. (A) The amount of sucrose unloaded was consistent across soil water potentials, except under the two highest phloem structural resistances (R4 \& R5). (B) The viscosity of the phloem sap increased as the soil water potential declined. At the highest pathway resistances (R4 \& R5), the model no longer gave steady state solutions (asterisks) due to a run-away increase in viscosity. (C) The velocity of phloem transport declined with decreasing soil water potential, as well as increasing resistance. (D) Phloem pressures declined with decreasing soil water potential in the lowest resistance phloem, but began increasing with declining soil water at the higher resistances (R3 - R5). The phloem pressure in the unloading zone (base, X shapes) remained at near $0 \mathrm{MPa}$ for the simulations tested which showed that there was not an unloading limitation. The maximum phloem pressure obtained that still researched a steady state was ${ }^{\sim} 2.4 \mathrm{MPa}$ (inverted triangles for R5 resistance @ $-0.3 \mathrm{MPa} \Psi \mathrm{s})$.

Figure 3. The impacts of the amount of sucrose unloaded to sink tissues over a soil dry-down while maximum loading rate (Vmax) was varied. (A) In an unloading unlimited scenario, whereby all sugar was removed from the unloading phloem area, increasing the loading rate had the consequence of increasing the sucrose output to the sinks under wetter soils (less negative soil water potentials). However, as the soil dried, the amount unloaded crashed to near zero as the run-away viscosity effect occurred. This was especially apparent in the higher loading rate scenarios, as phloem failure occurred in wetter soils. (B) The same simulation was run, except an unloading limitation was set such that sucrose started to accumulate in the unloading zone. In this scenario, only the slightly higher loading rate produced higher sucrose output over most soil water potentials, while the other loading rates exported significantly less. Overall, the effect of the unloading limitation was to make the phloem more susceptible to drought induced failure. In all simulations, the intermediate phloem resistance (R3) was used.

Figure 4. Sucrose output over varying soil water conditions and sucrose export rate, with pressure sensitive loading active. In this simulation, loading is regulated and stops past a phloem pressure of $2.4 \mathrm{MPa}$ and prevents the run-away viscosity event as evident in Figs. $2 \& 3$. (A) In an unloading unlimited scenario (see Fig. 3), sucrose output to sinks continues to increase with higher loading rates. Export amounts start to decline at lower soil water potentials, but never fall lower than the base loading rate export amount. (B) In an unloading limited scenario, similar results are shown to the unloading unlimited scenario. Overall, the effect of turgor regulated sucrose transporters were to prevent unloading limitation from becoming a bottleneck, and greatly lowered the impact of declining soil water potentials on the amount of sucrose exported form the phloem by preventing run-away viscosity. In all simulations, the intermediate phloem resistance (R3) was used.

Figure 5. The amount of sucrose export over varying soil water potentials as a function of phloem pathway resistance, with turgor regulation and the highest Vmax (140\%). Here turgor regulation allows phloem transport to operate over a wider array of soil water potentials and pathway resistances without resulting phloem transport failure due to the run-away viscosity effect. This simulation shows that a lower pathway resistance leads to the greatest amount of sucrose export, but that increased pathway resistance, while reducing export under drought, does not completely halt transport.

Figure 6. Sucrose output to sinks with varying stomatal properties $\left(G_{s} \Psi_{50} ; A, C\right)$ or $\left(G_{\max } ; B\right.$, D), while varying loading rate $(100 \%$ vs. $140 \%)$ or phloem pathway resistance (R1 vs R4). (A, B) In the two driest soil scenarios $(\Psi \mathrm{s}=-1 \mathrm{MPa})$, stomatal properties did not alter the amount of sucrose exported under both 
loading rates when phloem resistances were set to the lowest values (R1). However, once phloem resistance increased (R4), stomata that kept closed while dry (i.e., Gs $\Psi_{50}=-0.2$ or $\mathrm{G}_{\max }=40$ ) had a greater amount of sucrose exported than stomata that kept open (i.e., Gs $\Psi_{50}=-2.2$ or $G_{\max }=400$ ). (C, D) When the soil was wetter, stomatal influences had much less of an influence than when the soil was dry, except for some slightly reduced export at the higher phloem resistance and loading rates (red triangles).

Figure 7. The fraction of sucrose leaked out of the loading area as a function of phloem pathway resistance. Although increased phloem pathway resistance did increase the amount of sucrose that leaked back out of the loading zone by diffusion, the overall fraction that did leak out in either scenario was miniscule.

\section{Appendix A}

The fluid viscosity of phloem sap was calculated using

$v=v_{w} e^{\left(0.032 S f-(0.012 S f)^{2}+(0.023 S f)^{3}\right)}$ Eqn 1A

$S f=\frac{C p L * m m}{\rho}$ Eqn $2 \mathrm{~A}$

$\rho=\frac{\mathrm{CpL}}{1000} 0.1256+1.0019$ Eqn $3 \mathrm{~A}$

where $\rho$ and $v$ are the density and viscosity of the phloem sap. These equations follow Jensen et al. (2013), where $v$ is calculated from $v_{w}$, the viscosity of pure water at $200 \mathrm{C}$, and $S f$, the mass fraction of sucrose in the phloem $(\mathrm{w} / \mathrm{w})$, and $\rho$ is calculated as a linear function of phloem sucrose concentration. 


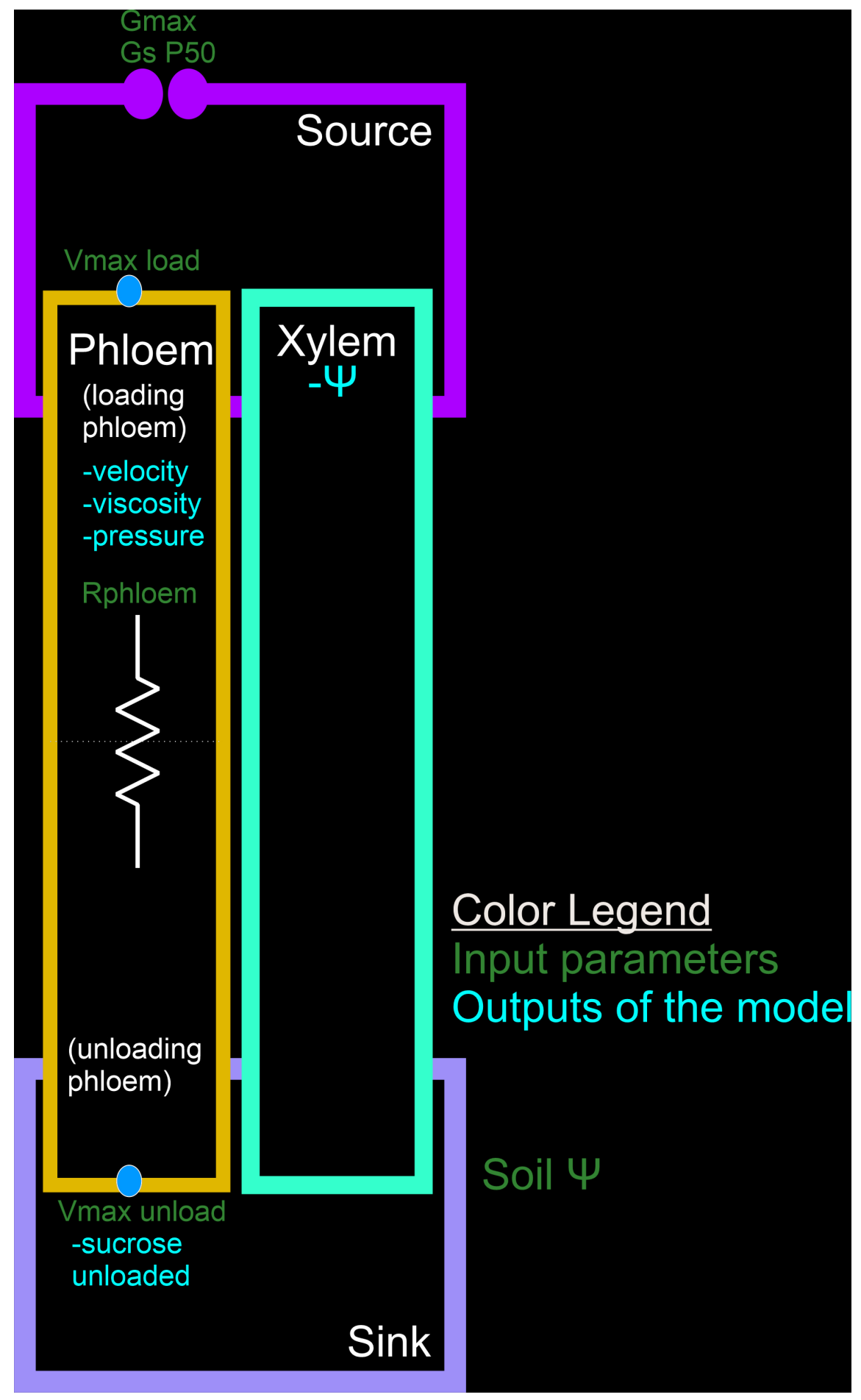



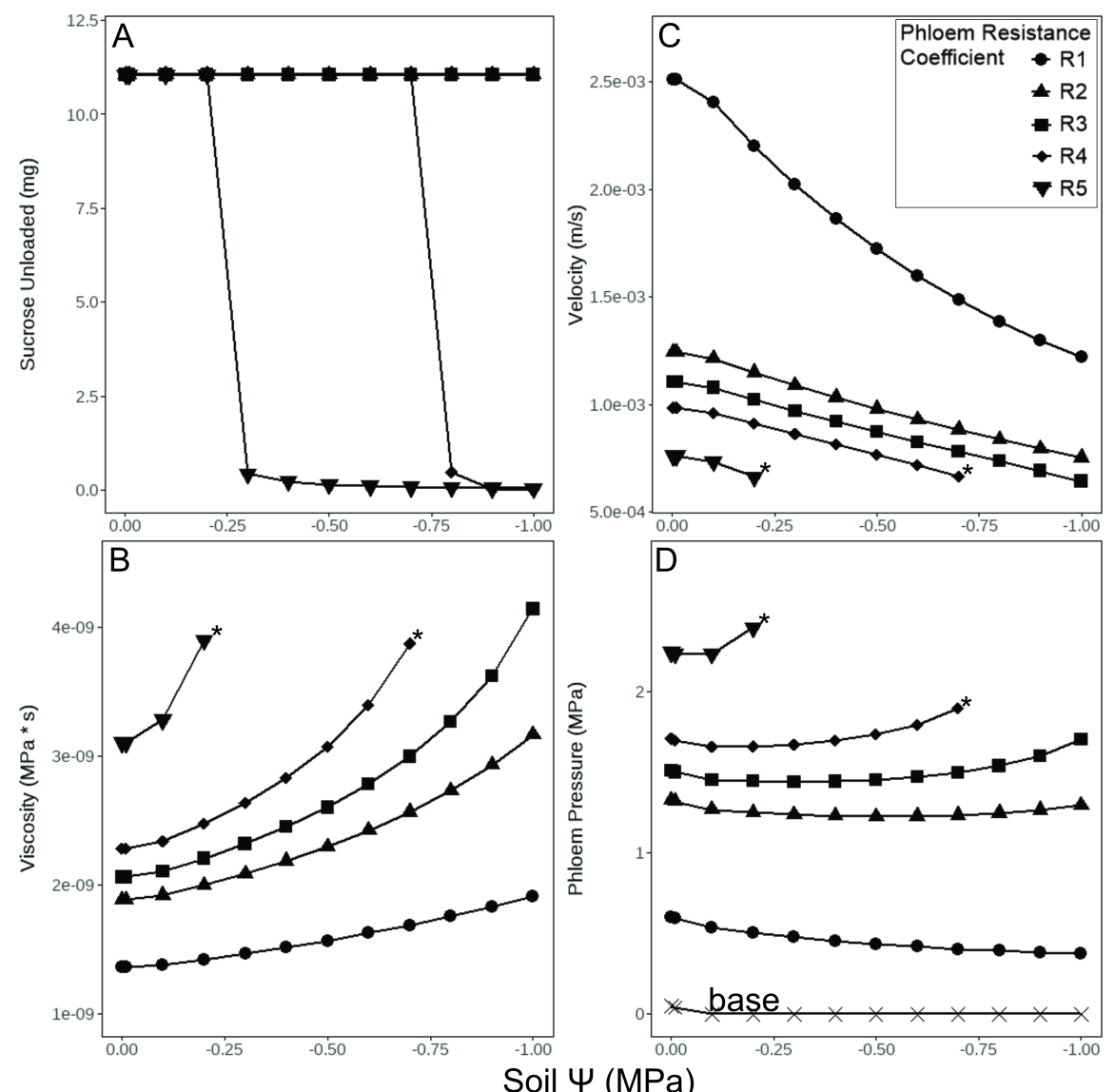

Soil $\Psi$ (MPa) 


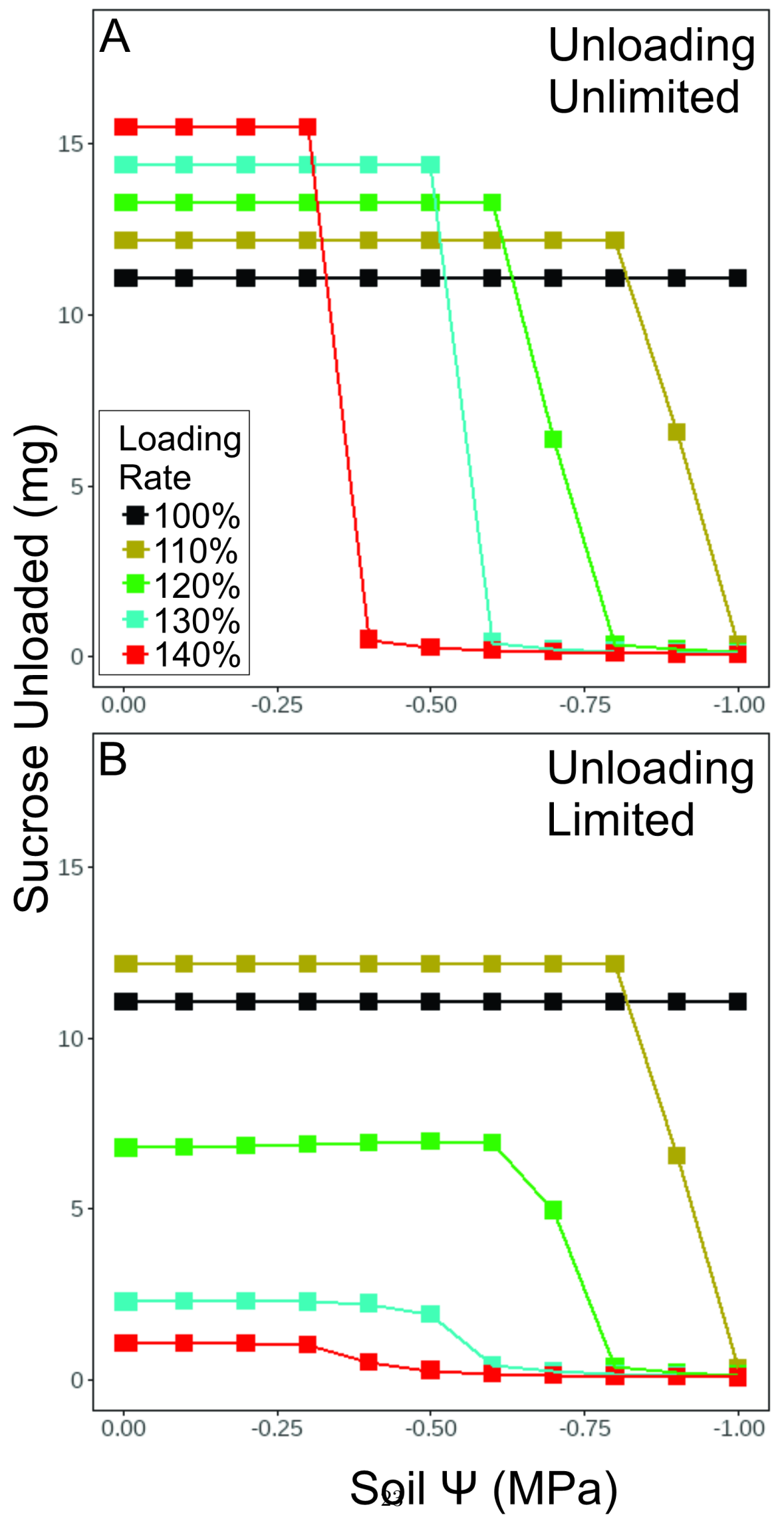




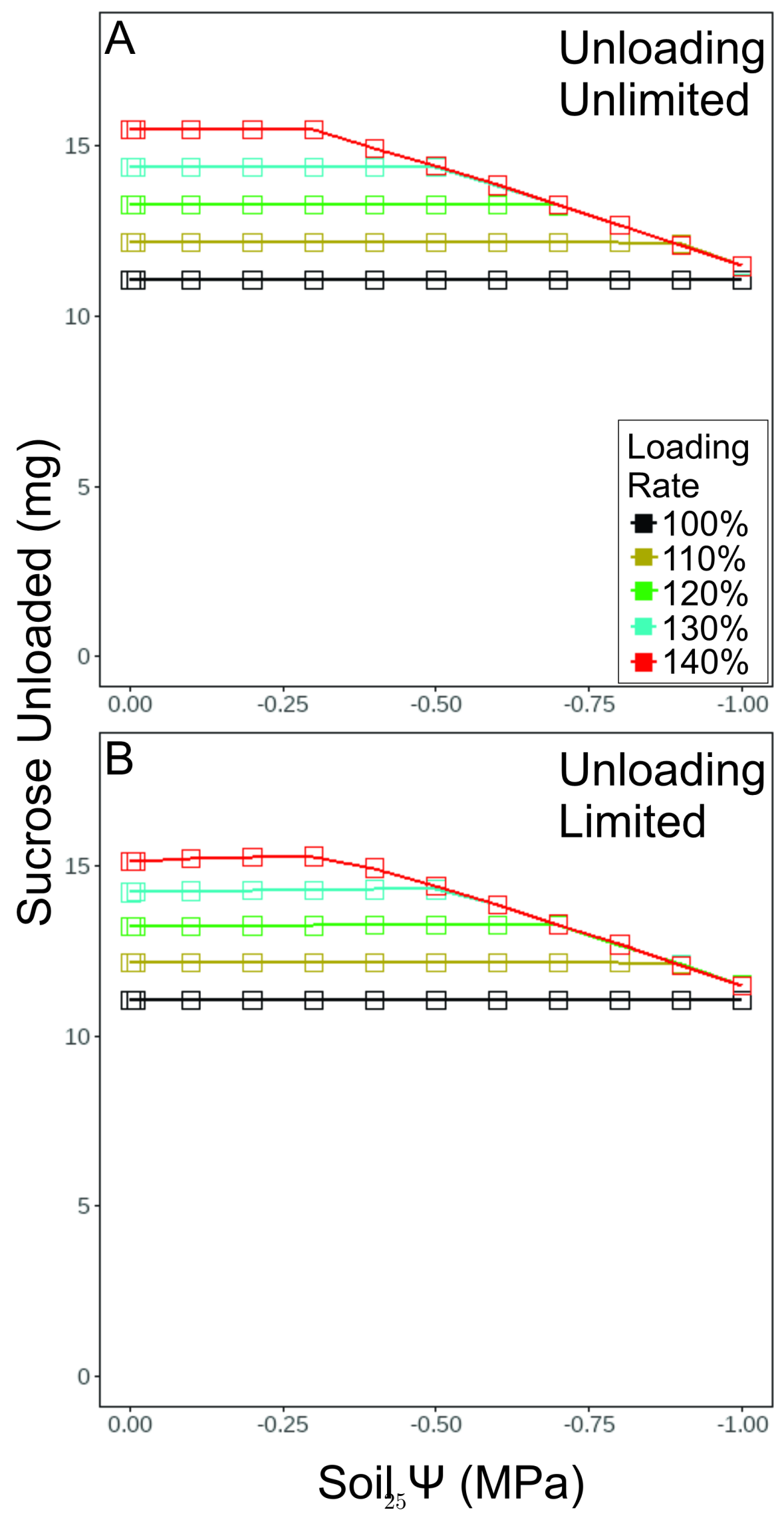




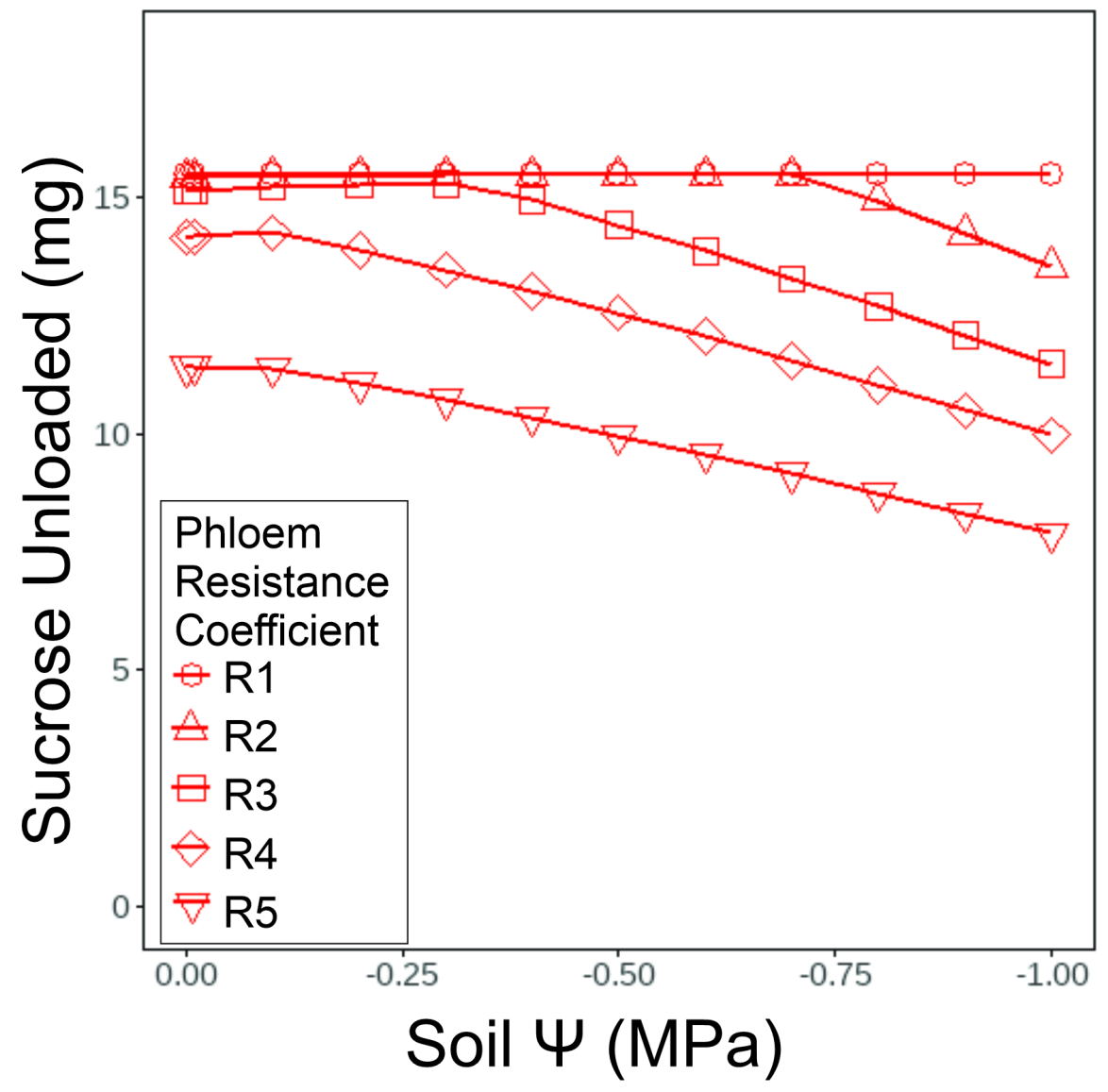



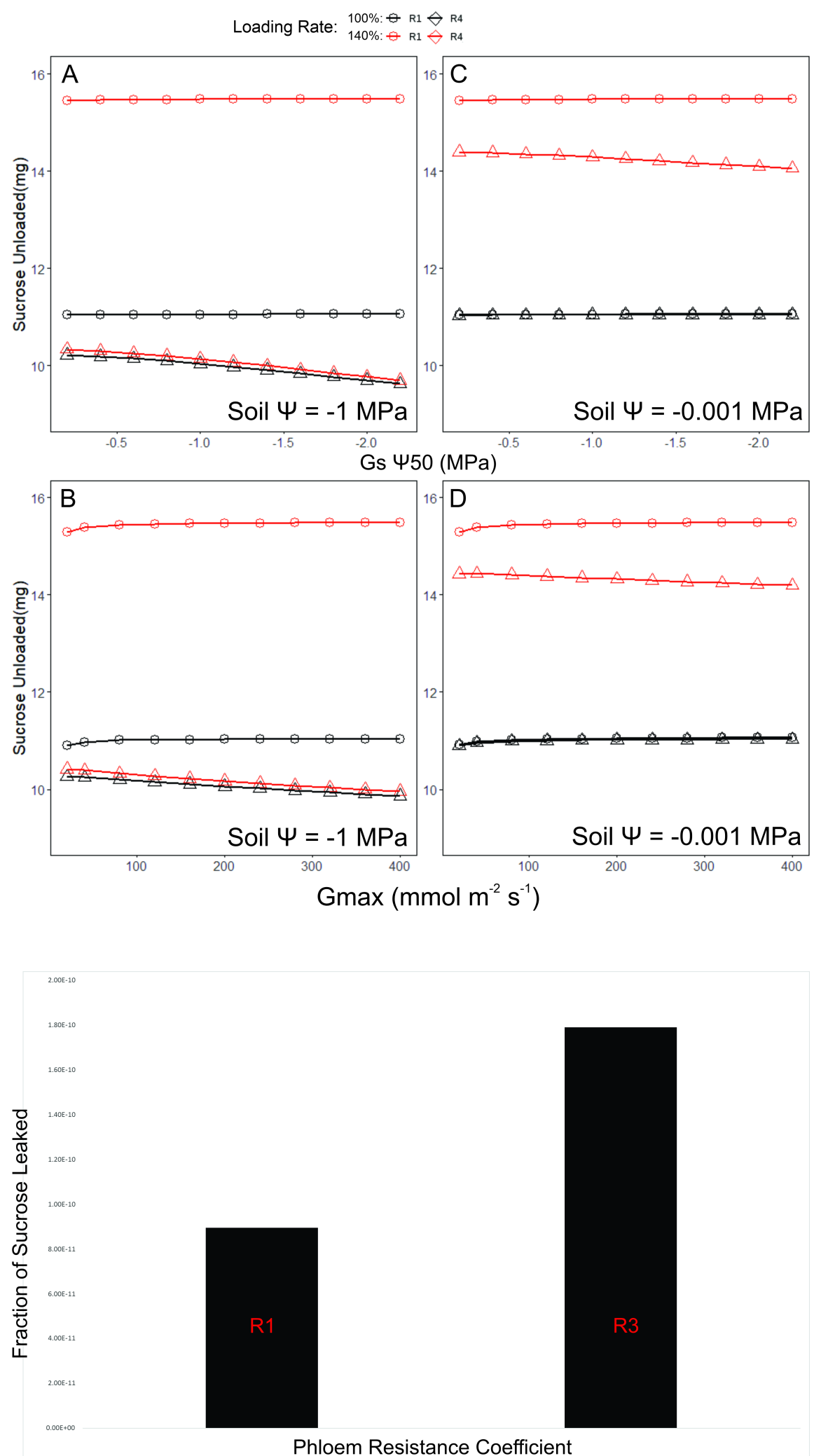